\title{
Tulane
}

Tulane Economics Working Paper Series

\section{Labor versus Capital in the Provision of Public Services: Estimating the Marginal Products of Inputs in the Production of Student Outcomes}

\author{
Ali Enami \\ Department of Economics \\ Tulane University \\ aenami@tulane.edu \\ Working Paper 1718 \\ Original version: September 2017 \\ This version: October 2017
}

\begin{abstract}
Does the enormous variation in financial resources available to local schools affect student achievement? There is an intense debate over the inequality of opportunity in public schools due to differences in financial resources, but there is little empirical evidence that sheds light on this issue. The main purpose of this paper is to measure the impact of various types of school expenditures (i.e. operating, minor capital, and major capital expenditures) on the short- and long-term educational achievement of students. This paper also looks at various channels (i.e. class size, attendance, discipline, and teachers' compensation) through which each type of expenditure could affect the performance of students. I use a dynamic regression discontinuity design that relies upon the exogenous variation in public school funding in Ohio that is created by marginally approved or failed local referenda to fund school districts. I find that only one type of expenditure, the approval of additional operating expenditures, has a positive effect in the short-term on the math proficiency of students subject to Ohio high school graduation tests, i.e. about 0.033 standard deviations $(0.27$ percentage points) for every additional $\$ 1,000$ extra per pupil operating expenditure. I also find that the subsequent increase in the average expenditure on instructional staff is the only channel that can explain this effect. I do not find any long-term effect for any type of school expenditures.
\end{abstract}

Keywords: public school funding, operating expenditure, minor and major capital expenditures, student achievement, school district referendum.

JEL codes: I20, H75, R51 


\title{
Labor versus Capital in the Provision of Public Services: Estimating the Marginal Products of Inputs in the Production of Student Outcomes ${ }^{1}$
}

\author{
Ali Enami \\ Department of Economics, Tulane University, 6823 St. Charles Avenue, New Orleans, LA \\ 70118, email: aenami@tulane.edu
}

(Working Paper: September 26, 2017)

\begin{abstract}
Does the enormous variation in financial resources available to local schools affect student achievement? There is an intense debate over the inequality of opportunity in public schools due to differences in financial resources, but there is little empirical evidence that sheds light on this issue. The main purpose of this paper is to measure the impact of various types of school expenditures (i.e. operating, minor capital, and major capital expenditures) on the short- and long-term educational achievement of students. This paper also looks at various channels (i.e. class size, attendance, discipline, and teachers' compensation) through which each type of expenditure could affect the performance of students. I use a dynamic regression discontinuity design that relies upon the exogenous variation in public school funding in Ohio that is created by marginally approved or failed local referenda to fund school districts. I find that only one type of expenditure, the approval of additional operating expenditures, has a positive effect in the short-term on the math proficiency of students subject to Ohio high school graduation tests, i.e. about 0.033 standard deviations ( 0.27 percentage points) for every additional $\$ 1,000$ extra per pupil operating expenditure. I also find that the subsequent increase in the average expenditure on instructional staff is the only channel that can explain this effect. I do not find any long-term effect for any type of school expenditures.
\end{abstract}

Keywords: public school funding, operating expenditure, minor and major capital expenditures, student achievement, school district referendum.

JEL classification: I20, H75, R51.

\footnotetext{
${ }^{1}$ I am very grateful to James Alm, Alan Barreca, Douglas Harris, Nora Lustig, Douglas Nelson, Jonathan Pritchett, Benjamin Sperisen, and participants in the Murphy Institute seminar series at Tulane University for their invaluable comments on earlier versions of this paper. I am especially thankful to David Brasington and Adam Isen for generously sharing their databases with me and to Michelle Beaulieu for her excellent research assistance. The financial support from the Department of Economics and School of Liberal Arts at Tulane University, as well as the Institute for Humane Studies at George Mason University, is acknowledged.
} 


\section{Introduction}

Economic theory and empirical studies consider human capital to be one of the most important determinants of success in the job market (Becker, 1964; Goldin and Katz, 2009). Similar to other goods and services, the production function for human capital (i.e. the education system) combines various inputs with the available educational technology to "produce" human capital. ${ }^{2}$ Analogous to other production functions, we expect that changing the levels of inputs, as well as changing the technology, will lead to higher levels of human capital. The main purpose of this paper is to examine the empirical evidence for this relationship. Specifically, I use a causal framework to look at various types of educational expenditures (i.e. operating, minor capital, and major capital expenditures) and their separate impacts on student test scores. I also look at several channels (i.e. student-teacher ratio, attendance rate, prevalence of disciplinary actions, and average expenditure on instructional staff) through which these effects can potentially take place. My results mainly indicate that only the operating expenditures, and exclusively through the increase in average expenditure on instructional staff, have a short-term effect on student test scores. Moreover, I do not find any effect in the long-run for any types of expenditures.

Understanding the relationship between various types of school expenditures and student outcomes has important policy implications. Public school funding in the Unites States varies significantly due to the role of local resources in funding public schools. This variation in funding has led to an inequality of opportunity for some students (Jennings, 2012), showing up in a low probability of upward mobility for children of low income families (Breen, 2010; Brown, 2013). Since a centralized school funding system that provides all school districts with identical per pupil funding is not politically viable in many states, policy makers who want to provide equitable schooling must pursue other policy options. One option is to focus federal and state resources on areas that have the most impact on improving the educational attainment of students in disadvantaged school districts. By examining the effect of various types of expenditures (i.e. operating, minor capital, and major capital expenditures) on educational

\footnotetext{
${ }^{2}$ One can rely on the same terminology to describe the elements of other production functions. For example, teachers can be viewed as those who provide the "labor" and school facilities act as the "capital" input of this production function. The curriculum, teaching techniques, computers and other educational enhancing software and hardware can be grouped as the elements of "technology" in this "production" function. The outcome, human capital, is harder to measure, but proxies such as test scores and measurable social skills are the indicators that are used to evaluate the output of this "production" function.
} 
outcomes and the channels through which these effects take place, this study aims to shed light on choices faced by policymakers when allocating educational funds.

While the relationship between school expenditures and educational outcome is theoretically straightforward, empirical studies do not agree on the importance of the financial resources in producing better student outcomes. The famous Coleman report (Coleman et al., 1966) is the first empirical study to investigate the role of "school quality" ${ }^{3}$, and it finds that school quality has a relatively low average impact on the achievement of students, with the socio-economic status of their families playing the major role. However, this report also finds that the quality of schools significantly benefits the most economically disadvantaged groups. Follow-up studies have found conflicting evidences in support (Hanushek, 1986; Cellini et al., 2010; Neilson and Zimmerman, 2014; Hong 2016; Martorell et al., 2016) and against (Greenwald, 1996; Card and Krueger, 1996; Jackson et al., 2016) the Coleman report. These conflicting views are not limited to the individual studies, and even meta-analyses disagree about which side of the argument has produced more reliable evidence in support of their case. ${ }^{4}$ In order to resolve this disagreement and to better understand the true effect of school expenditure, some studies have shifted their focus to long-term outcomes such as income in adulthood. These results have also been inconclusive (Card and Krueger, 1996), although more recent papers, equipped with better data and a more reliable causal framework, have found positive evidence relating school spending to better educational outcomes and eventually higher future income (Jackson et al., 2016).

Despite this extensive body of work and its many important contributions, there are significant limitations in the previous work. The most important ones are the lack of a proper causal framework and the correlational nature of the majority of previous empirical studies (Jackson et al., 2016). More recent work has addressed these issues; for example, see Cellini et al. (2010), Hong and Zimmer (2016), Jackson et al. (2016), and Martorell et al. (2016). However, even these more recent studies have not eliminated all of the limitations in the previous work on this topic, mainly that they do not look at various types of school expenditures within a comprehensive framework. In other words, they either employ a causal framework that only allows them to focus on total expenditures of schools (e.g., Jackson et al., 2016; Kogan et al.,

\footnotetext{
${ }^{3}$ In this report, the quality of schools is measured based on "...curriculums offered [(i.e. academic, commercial, and vocational)], school facilities such as textbooks, laboratories, and libraries, such academic practices as testing for aptitude and achievement, and the personal, social, and academic characteristics of the teachers and the students bodies in the schools" (Coleman et al., 1966).

${ }^{4}$ For an example of these conflicting views see the exchange between Hanushek (1994) and Hedges et al. (1994).
} 
2016; Lavertu and St. Clair, 2017) or their data limit their focus to the major capital expenditures (e.g., Cellini et al., 2010; Hong and Zimmer, 2016; and Martorell et al., 2016). The current paper addresses these problems by incorporating both a causal framework and a database that allows for the evaluation of the impact on student outcomes of various types of educational expenditures (i.e. operational, minor capital, and major capital expenditures).

In a perfectly designed experimental study, one would randomize the distribution of various types of expenditures across school districts and then measure the resulting effects on student outcomes. Such an experiment is highly expensive and difficult to undertake on a large scale. Because of this limitation, I use an alternative quasi-experimental approach that mimics a largescale experiment of the type discussed above. ${ }^{5}$ Specifically, I use the Ohio laws that require school districts to rely on local referenda to change the amount of revenue that they receive through local resources and that also require districts to specify the purpose of additional requested funding. These laws have resulted in numerous referenda for various purposes that can be generally categorized as operating, minor capital, and major capital expenditures. While the probability of approving an additional local tax may not be random, it mimics a random assignment when one focuses on the referenda that are passed or failed with a "small" votemargin (Cellini et al., 2010); that is, conditional on having a close election, a school district ending up above the 50 percent required threshold (and so receiving extra educational funding) or below it (and so not receiving any additional funding) is as good as a random assignment. Given this randomized distribution of financial resources across school districts, any observed effect on student outcomes will have a causal interpretation. Similarly, this framework allows for the causal analysis of the channels through which additional funding for various purposes relates to an educational outcome.

Since the effect of school funding on student outcomes may not reveal itself immediately, I look at both short-term (1 year) and long-term (up to 5 years) effects. ${ }^{6}$ The main practical challenge of studying the long-term effect is that those school districts that marginally reject an additional local tax (i.e. the control group) may approve it in the next referendum. Such noncompliance would lead to the attenuation bias, so that it would appear as if the extra funding has no effect on the educational outcome in the long-run. To account for the dynamic nature of

\footnotetext{
${ }^{5}$ Cellini et al. (2010) are the first to employ this approach in the context of school funding.

${ }^{6}$ For the case of major capital expenditures, this paper also looks at effects up to 10 years following the approval of a project by voters.
} 
school funding, I use a modified version of an innovative estimation technique originally proposed by Cellini et al. (2010). The methodology section of this paper discusses this technique in great detail, but it can be summarized as follows. The effect of approving additional funding for a school district in year $t$ affects student outcomes in year $t+\tau$ directly and also indirectly through its effect on the probability of approving other funding proposals between these two points in time. These other proposals also have a direct and indirect effect on student outcomes in year $t+\tau$, which the framework proposed by Cellini et al. (2010) takes into account. My modification to the original model is to allow for the school funding to be more than just one type, and also to incorporate a difference-in-differences structure within it. The latter requires a significantly less restrictive identifying assumption since it only requires the treatment and control groups to have a "parallel trend" in the level of outcome variables, as opposed to requiring identical levels.

The main student outcome that I examine is the district level math proficiency rate $^{7}$ of students who are subject to Ohio high school graduation tests in school years 1996-97 through $2014-15^{8}$. These tests are administered to $9^{\text {th }}$ graders prior to 2006 and $10^{\text {th }}$ graders afterward. ${ }^{9}$ I also look at four possible channels through which the additional school funding can affect the students' attainment: class size (student to teacher ratio), student attendance rate, discipline (disciplinary actions per 100 students), and average expenditure on instructional staff. My preferred model allows for the heterogeneous treatment assignment by accounting for the fact that school districts that receive additional funding following a close referendum do not necessarily receive the same per pupil amount. Moreover, I compare the effect of extra funding on schools located in relatively poor neighborhoods versus the ones located in relatively rich ones.

I find a positive and statistically significant effect for the additional operating expenditures in the short term, i.e. 0.033 standard deviations (0.27 percentage points) increase in math proficiency rate one year following the commencement of a new tax, and no effect for additional

\footnotetext{
${ }^{7}$ The Ohio Department of Education categorizes students in five groups based on their test scores: "limited", "basic", "proficient", "accelerated", and "advanced". Throughout this paper, the proficiency rate is calculated based on those students that score "proficient" or above in a test. The minimum percentage of correct answers necessary to be proficient in a subject varies slightly for different subjects and from one year to another, but it is generally about 42 percent.

${ }^{8}$ The reason to choose this specific test score is because it is available for more years.

${ }^{9}$ This paper normalizes the math proficiency rates in each year to account for the changes in tests and the grades of students who took them.
} 
minor or major capital expenditures. The latter is in line with the findings of Cellini et al. (2010) and Mortell et al. (2016), who did not find any significant effect of the additional major capital expenditures on test scores in the context of California and Texas public schools. ${ }^{10}$ To the best of my knowledge, the positive effect of operating expenditures on the student test scores found in this study is the first causal evidence for the effect of this type of expenditure. Moreover, I find that this effect is mainly driven by the additional expenditure on the instructional staff. This is contrary to the findings of Fryer (2013) who did not find a causal relationship between financial incentives of teachers and student outcomes. In the context of Ohio's public school system, additional funding for school districts, regardless of whether it is for operational, minor capital, or major capital expenditures, has an economically negligible effect on class size, attendance rate, and discipline of students. Finally, I provide causal evidence showing that better funding has a significantly greater effect on school districts located in relatively poor neighborhoods, about four to nine times of the average effect in various years.

The contribution of this paper to the literature is threefold. First, to the best of my knowledge, this is the first paper that, in addition to using a causal framework, differentiates between various types of expenditures by the public school system. While I limit my analysis in this paper to three types of expenditures, i.e. operating, minor capital, and major capital expenditures, my framework can be easily extended to accommodate more categories. As a result, this paper provides the first empirical evidence for the causal effect of operating expenditures on student outcome. Second, this paper examines various channels through which each type of funding could affect the test score of students. Previous work either did not examine channels or did so in a limited way. Finally, this paper improves the dynamic regression discontinuity design proposed by Cellini et al. (2010) by incorporating a difference-indifferences structure (as opposed to the single-difference structure of the original model).

The rest of this paper is organized as follows. Section II reviews the various aspects of public school funding in Ohio. Section III presents the theoretical framework of this paper, and section IV describes the empirical methodology of this study and provides a detailed description of the improved dynamic regression discontinuity design utilized in this paper. Section V introduces the data sources along with descriptive statistics and the results of the parallel trend

\footnotetext{
${ }^{10}$ Some studies have found statistically significant effect of building schools on educational outcome in the U.S. (e.g. Hong and Zimmer, 2016) and in developing countries (e.g. Duflo, 2001).
} 
tests. Section VI presents the results of the preferred model along with various robustness checks. Section VII concludes with suggestions for future research.

\section{Public School Funding in Ohio}

In the 2015-16 school year, public schools in Ohio spent about \$9,915 per pupil (ODE, 2017). Between 1991 and 2013, Ohio has been ranked about 19th on average among 50 states and the District of Columbia in per pupil expenditures (NCES, 2017). About 10\% of the total school expenditures in Ohio have been consistently spent on construction projects, school maintenance, and renovations, while around 45 percent are spent on the salary and benefits of the instructional staff (NCES, 2017). ${ }^{11}$ As Figure 1 shows, Ohio is very similar to the rest of the U.S. in terms of the share of expenditures on capital structures versus instructional staff.

[Figure 1 about here]

As of March 2017, Ohio has 612 traditional school districts that cover the whole state and are mainly funded through the local sources. ${ }^{12}$ As Figure 2 shows, about 50 percent of the total school budget in Ohio has been consistently financed by local sources, which makes this state a good representative of the Unites States as a whole (NCES, 2017). The remaining 50 percent is divided between resources provided through the state (40 percent) and the federal government (10 percent). The federal funding for schools in Ohio is similar to the rest of the country in that resources are allocated through nation-wide programs such as No Child Left Behind or the American with Disability Act.

[Figure 2 about here]

State funding for schools in Ohio has experienced various changes over the years and has been the subject of four state Supreme Court litigations. ${ }^{13}$ The main approach has been to fund schools based on a per-pupil formula that takes into account the ability ${ }^{14}$ of school districts to raise taxes (ODE, 2017). ${ }^{15}$ This is known as the "foundation" formula which determines how

\footnotetext{
${ }^{11}$ The rest of the $45 \%$ is divided between expenditures on non-instructional staff, supplies and supports, and "nonspecified" expenditures.

${ }^{12}$ We limit the domain of this study to these traditional school districts. As of March 2017, Ohio has 49 joint vocational school districts, and approximately 370 public community schools (i.e. charter schools) that are not included in this analysis.

${ }^{13}$ For a good review of the historical and recent approaches to school funding in Ohio, see Pittner et al. (2010)

${ }^{14}$ The ability reflects the value of properties in a school district, its median income, and the average federal adjusted gross income of its residents.

${ }^{15}$ The only exception to this main approach happened in fiscal years 2010 and 2011, in which an "Evidence Based Model" was used. This model identifies the needs of students in different groups in financial terms and then
} 
much funding a school district should receive through the State government to achieve the minimum per pupil funding that it should have (also determined by the State government). The problem with this approach is that legislators use the available budget, not the actual needs of students which usually exceeds the available budget, to determine the minimum per pupil revenue that a school district should receive. Historically, this approach has resulted in the underprovision of funding for low-income districts and the creation of one of the most unequal school funding systems in the U.S. by 1991 (Pittner et al. 2010). The four Ohio Supreme Court decisions ${ }^{16}$, which all found the school funding system to be unconstitutional, did not force a specific new system. As a result, the main problem with the system (i.e. its reliance on local funding) has remained unchanged. By 2009, Ohio is still ranked high (19th) in terms of inequality in its public-school funding (Pittner et al. 2010). However, these litigations have had some positive impacts, such as the creation of the Ohio School Facilities Commission (in 1997). As part of its programs, the Commission provides matching funds ${ }^{17}$ for districts to build new schools (OFCC, 2017). ${ }^{18}$

Local funding for school districts in Ohio is provided through property and income taxes. In 2017, 190 school districts in Ohio use income taxes ( 0.25 percent to 2 percent) in addition to the property taxes to support their mission (ODT, 2017). School districts can also issue bonds in order to finance major capital investments and (additional) property taxes are used to pay back the borrowed money and interest. Ohio laws require any income tax in excess of 1 percent municipal tax and any property tax that exceeds an aggregate 10 mills per dollar valuation ${ }^{19}$ of a property to be subjected to the decision of voters, and a single majority vote is sufficient to pass a new tax (OSOS, 2017). The school districts are required to identify the "purpose" of a tax, which allows this study to determine whether the purpose of a tax is to fund a type of

allocates money to schools based on the population of students in these groups. This model was abandoned following the election of a new Governor (i.e. John Kasich).

${ }^{16}$ The cases are known as DeRolph (I through IV) vs. State, and were litigated between 1997 and 2002 by the supreme court of Ohio. The first case was filed in a lower court in 1991.

${ }^{17}$ As of February 2017, depending on the wealth of a district, the share of state in these projects ranges from $12 \%$ to $98 \%$ in various projects. There is also one project that is funded $100 \%$ by the state. School districts are ranked based on their need and they have 13 months from the time that their project is approved to raise their local share (through bond referendums). If a school district fails to raise its local share within this time limit, it is considered a "lapsed" district but it can still receive the funding at a later time if it gets the necessary vote to raise the local share of the necessary funding for its project (OFCC, 2017).

${ }^{18}$ The age and condition of schools in relatively poor districts were among main motivations for these school districts to sue the State in the first place.

${ }^{19}$ Practically, all new property taxes that have passed in the past two decades are in addition to this 10 mills threshold. 
"operational expenditure" versus "minor capital expenditure". Bonds are always classified as a "major capital expenditure". The following are examples for a property tax levy (hereafter levy), a bond, and an income tax proposal:

\section{Proposed Tax Levy}

Urbana City School District

A renewal of a tax for the benefit of the Urbana City School District for the purpose of current operating expenses at a rate not exceeding 14.8 mills for each one dollar of valuation, which amounts to $\$ 1.48$ for each one hundred dollars of valuation, for a continuing period of time, commencing in 2016, first due in calendar year 2017.

\section{Proposed Bond Issue}

\section{Urbana City School District}

Shall bonds be issued by the Board of Education of the Urbana City School District for the purpose of paying a portion of the local share of school construction under the State of Ohio Classroom Facilities Assistance Program and other improvements, including construction of a new high school and K-8 building, handicap accessibility and security measures, equipment, furnishings, and site improvements, together with all necessary appurtenances thereto, in the principal amount of \$31,355,000 to be repaid annually over a maximum period of 28 years, and an annual levy of property taxes be made outside the ten-mill limitation, estimated by the county auditor to average over the repayment period of the bond issue 7.15 mills for each one dollar of tax valuation, which amounts to $\$ 0.715$ for each one hundred dollars of tax valuation, commencing in 2014, first due in calendar year 2015, to pay the annual debt charges on the bonds, and to pay debt charges on any notes issued in anticipation of those bonds?

\section{Proposed Income Tax}

Northeastern Local School District.

Shall an annual income tax of 1 percent on the earned income of individuals residing in the school district be imposed by the Northeastern Local School District, for a continuing period of time, beginning January 1, 2014, for the purpose of current expenses?

What makes Ohio special compared to other states is a 1976 legislation known as House Bill (HB) 920. According to HB 920, any property tax approved by voters is frozen based on the valuation of a property in the year of referendum, and therefore, the dollar value that is received by a school district remains constant for the duration of the approved levy. As a result, HB 920 has forced district boards of education in Ohio to use new referenda regularly (and also to rely on income tax) to keep up with the financial needs of their districts. Panels A, B, and C of Table 1

provide a descriptive statistic of all school district referenda in Ohio from 1996 to 2015 for bonds, levies, and income tax referenda respectively. 
[Table 1 about here]

Panel A of Table 1 provides the summary statistics of bond referenda for school districts in Ohio between 1996 and 2015. The total number of referenda in one year varies between 24 and 138 and the average size of these bonds ${ }^{20}$ varies between $\$ 6,918$ and $\$ 14,695$ (constant-2015 dollars) per pupil. The average length of these bonds exceeds 24 years and the approval rate is variable in different years from as low as 26 percent to as high as 67 percent. Panel B of Table 1 presents the summary statistics for school district related levies that were voted on between 1996 and 2015. In comparison to the other two types of referenda (i.e. bond and income tax) the number of levies on the ballot is almost three times more than the other two. The total number of levies in one year reaches its highest level in 2004 with 479 issues on the ballot. The share of levies related to a minor capital expenditure varies between 22 percent and 46 percent in different years. The average size of levies ${ }^{21}$ ranges between $\$ 593$ and $\$ 861$ per pupil per year in various years. The average length of a levy that is not for the continuing period of time (CPT) is about 5 to 8 years. The percentage of levies that are for CPT is between 14 percent and 30 percent over this time period. The approval rate of levies is more than bonds, and with the exception of one year, never drops below 55 percent.

Finally, Panel C of Table 1 provides the summary statistics of income tax referenda to fund school districts in Ohio between 1996 and 2014. ${ }^{22}$ The number of income tax referenda in a year is generally the lowest of the three types, but increases over time and exceeds the number of bonds in some recent years. The average size of income tax proposals ${ }^{23}$ is similar to that of tax levies but slightly higher and varies between $\$ 805$ and $\$ 1,317$ per pupil per year in various years. A big distinction between income tax and levy proposals is that a much lower percentage of the former is for minor capital expenditures only. In fact, there are years with zero income tax proposals to increase minor capital expenditures. With the exception of 2014, the average share of proposals to increase capital expenditures through an additional income tax is less than 14

\footnotetext{
${ }^{20}$ I use the dollar value a bond mentioned on the ballot to calculate any dollar values associated with a bond.

${ }^{21}$ The size of a levy is calculated based on the millage rate of the issue on the ballot and the total taxable value of the properties in a school district.

${ }^{22}$ The income tax referenda for school year 2015-16 are not presented in the table due to the fact that necessary information to calculate the size and per pupil size of the tax issues on the ballot has not been released by the ODT as of March 2017.

${ }^{23}$ To calculate the dollar value of an income tax proposal, I use the rate specified in the issue on the ballot and the total "federal adjusted gross income" of individuals living in a school district. The Ohio taxable income (which is not available at the district level for some years in the data) is about $95 \%$ of the "federal adjusted gross income", so I multiply the values by 0.95 to impute the size of the income tax proposals.
} 
percent of all income tax referenda in a year. The length of non-CPT income tax proposals and the percentage of the CPT tax proposals are very similar to that of levies discussed above. Finally, the approval rate of income tax proposals is generally between bonds and levies and varies between 26 percent and 64 percent.

\section{Theoretical Framework}

Facing the question of whether and how to allocate financial resources to a school, a rational median voter makes her decision in a way that maximizes her utility. To analyze her decision, one needs to look at the type of " $\operatorname{good}(\mathrm{s})$ " that a school would produce. To keep the model tractable, I bundle all possible goods into two groups, "educational (E)" and "non-educational $(\mathrm{NE}) "$ goods $^{24}$, and treat each group as if it were a simple and homogenous good. ${ }^{25}$ As it is discussed later, if schools produce more than one good, the marginal products of various inputs in the production of each good do not have to be equal. For example, an operating expenditure can have a higher marginal product in producing E, while a capital expenditure can have a higher marginal product in producing NE. This is a key theoretical result and explains, for example, why rational voters may continue to approve major capital projects while the empirical studies (including this one) have failed to find any evidence that such expenditures lead to better educational outcomes. More importantly, this theoretical result explains why, for example, rational voters may prefer such capital expenditures over an increase in operating expenditure that have an actual effect on the educational outcome of students.

To explain the model, first assume the simplest case in which various types of school expenditures produce only educational goods:

$$
E=f(L, K, .)
$$

where $L$ and $K$ stand for labor and capital and "." is the placeholder for any other input in the production function. Assume there are only two types of school expenditures: ${ }^{26}$ operating expenditures $(O)$ that only affect the labor and capital expenditures $(C)$ that only affect capital in the above production function, i.e.

$$
l=g(O)
$$

\footnotetext{
${ }^{24}$ Examples of non-educational goods are: lower crimes, a school swimming pool that is open to all members of the community, and after school care for students (beyond the educational value of the afterschool programs)

${ }^{25}$ The main conclusions of the model remain unchanged if the number of goods exceed the two goods mentioned here.

${ }^{26}$ The main conclusions of the model remain unchanged if the types of the school expenditures exceed the two types mentioned here.
} 


$$
K=h(C)
$$

To keep the model simple, I assume the depreciation is zero. We can rewrite the educational attainment production function to be a direct function of operating and capital expenditures. Moreover, given a budget constraint for school expenditures $(\bar{S})$ and some regularity assumptions about the production function, a decision maker faces the following optimization problem in regard to how to allocate operating and capital expenditures to a school district: ${ }^{27}$

$$
\begin{gathered}
\text { Max } E=E(O, C, .) \\
\text { Subject to: } O+C=\bar{S}
\end{gathered}
$$

The first order conditions of this simple optimization problem require that the marginal product of one dollar spent on operating expenditures to be equal to the marginal product of one dollar spent on capital expenditures. i.e.

$$
\frac{\partial E}{\partial O}=\frac{\partial E}{\partial C}
$$

Given that there are no particular assumptions about the functional form of the educational attainment production function, the above equation is a very specific theoretical result that could be tested empirically. However, there is an initial strong assumption about the type of goods a school produces. The model assumes it is only educational goods. This is not a realistic assumption. For example, an after-school program that helps students improve their understanding of the class materials keeps them from being on the street and from being involved in crimes as well. This increase in safety is a non-educational "good" (NE) that is valuable to a median voter. Therefore, a better theoretical model is the one that includes these types of non-educational goods in the decision making of how to invest in schools.

Assume the median voter in a school district has the following utility function that she wants to optimize given her budget constraint:

$$
\begin{gathered}
\text { Max } U=U[E(O, C, .), N E(O, C, .), e] \\
\text { Subject to: } O+C+\bar{P}_{e} e=\bar{B}
\end{gathered}
$$

\footnotetext{
${ }^{27}$ Note that if there is only one good that various types of school expenditures can produce, and the amount of financial resources is fixed, the utility function of the decision maker becomes irrelevant in regard to how the fixed budget should be distributed among the different types of school expenditures. The utility function is a relevant factor in determining how much money should be spent on schools (as opposed to other goods) but does not affect the conclusions of the simple model discussed here.
} 
I assume no specific functional form for this utility function and only that it is strictly increasing, strictly concave, and at least two times differentiable (i.e. the regularity assumptions). The median voter has to decide how to spend her limited budget $(\bar{B})$ on operating and capital expenditures in her school district as well as everything else $(e)$. I assume the price of other goods and services $\left(\overline{P_{e}}\right)$ is exogenous and therefore given. This is a reasonable assumption since a local school district does not have that much power to affect the general prices. The Lagrangian function and the first order conditions of this optimization problem are as follows: ${ }^{28}$

$$
\begin{array}{r}
L=U[E(O, C, .), N E(O, C, .), e]+\lambda\left(\bar{B}-O-C-\bar{P}_{e} e\right) \\
\frac{\partial U}{\partial O}=0 \rightarrow\left(\frac{\partial U}{\partial E} \times \frac{\partial E}{\partial O}\right)+\left(\frac{\partial U}{\partial N E} \times \frac{\partial N E}{\partial O}\right)=\lambda \\
\frac{\partial U}{\partial C}=0 \rightarrow\left(\frac{\partial U}{\partial E} \times \frac{\partial E}{\partial C}\right)+\left(\frac{\partial U}{\partial N E} \times \frac{\partial N E}{\partial C}\right)=\lambda
\end{array}
$$

Since the right-hand side of the two first order conditions are the same, the left-hand side must be the same too:

$$
\left(\frac{\partial U}{\partial E} \times \frac{\partial E}{\partial O}\right)+\left(\frac{\partial U}{\partial N E} \times \frac{\partial N E}{\partial O}\right)=\left(\frac{\partial U}{\partial E} \times \frac{\partial E}{\partial C}\right)+\left(\frac{\partial U}{\partial N E} \times \frac{\partial N E}{\partial C}\right)
$$

After some manipulation, we have the following equation:

$$
\rightarrow \frac{\partial E}{\partial O}-\frac{\partial E}{\partial C}=\left(\frac{\frac{\partial U}{\partial N E}}{\frac{\partial U}{\partial E}}\right)\left(\frac{\partial N E}{\partial C}-\frac{\partial N E}{\partial O}\right)
$$

Our prior assumptions about the utility function allows us to sign the scaling term on the righthand side, i.e. $\left(\frac{\frac{\partial U}{\partial N E}}{\frac{\partial U}{\partial E}}\right)$. I assumed the utility function is strictly increasing, and therefore, both partial derivatives are positive. We can simplify this equation to be as follows:

$$
\rightarrow \frac{\partial E}{\partial O}-\frac{\partial E}{\partial C}=Z\left(\frac{\partial N E}{\partial C}-\frac{\partial N E}{\partial O}\right) \quad \text { where } z>0
$$

This equation implies a relatively specific conclusion:

\footnotetext{
${ }^{28}$ Only the relevant first-order conditions are included here.
} 


$$
\left\{\begin{array}{l}
\frac{\partial E}{\partial O}>\frac{\partial E}{\partial C} \leftrightarrow \frac{\partial N E}{\partial O}<\frac{\partial N E}{\partial C} \\
\frac{\partial E}{\partial O}<\frac{\partial E}{\partial C} \leftrightarrow \frac{\partial N E}{\partial O}>\frac{\partial N E}{\partial C}
\end{array}\right.
$$

This means if the marginal product of one dollar spent in a school district as an operating expenditure exceeds the marginal product of one dollar spent as a capital expenditure in the "production" of the "educational" good, it has to be the case that a reverse relationship exists between these two marginal products in the context of the production of "non-educational goods" by that school district.

While it is much harder to empirically test the above equation ${ }^{29}$, it provides a good explanation for why a rational median voter could deviate from equalizing the marginal products of an additional dollar spent on various types of school expenditures (i.e. deviate from equation 5). In fact, this paper provides some evidence for this deviation in which the marginal product of operating expenditures exceeds the marginal product of capital expenditures. The above theory therefore suggests that capital expenditures have to have a greater marginal product in producing non-educational goods (a prediction that this paper cannot).

\section{Empirical Methodology}

School funding that is provided through local referenda has a unique dynamic. Although one can rely on referenda that are marginally approved or rejected (i.e. a sharp regression discontinuity) as a way to create a quasi-randomized assignment of funding to school districts, those school districts that fail to receive funding may ask for it again in the next period and receive it. As a result, there is a non-compliance issue that is quite different from a usual fuzzy regression discontinuity and cannot be addressed by the techniques devolved for this type of regression discontinuity. ${ }^{30}$

Without accounting for the dynamic nature of the school funding through referenda, one can estimate the intent-to-treat (ITT) effect by simply comparing the educational outcome of school districts that receive extra funding in referenda with small vote margins (i.e. the treatment group) to school districts that fail to receive additional funding in similar other close referenda (i.e. the

\footnotetext{
${ }^{29}$ That is because finding an acceptable proxy for noneducational goods is not as easy as the commonly used proxies in the literature for educational goods (e.g. test scores).

${ }^{30}$ The type of non-compliance that the usual fuzzy regression discontinuity models address is the one that happens at the time of treatment assignment. The non-compliance in the case of school funding mainly happens in the years following the year of treatment assignment.
} 
control group). Unfortunately, the ITT estimates are biased toward zero due to the noncompliance problem mentioned above. The main goal of this section is to show how one can go from the easily estimated ITT effects to more interesting but complex treatment-on-the-treated (TOT) effects. The latter is the effect of school funding on the student outcome in the absence of the non-compliance issue. In other words, the TOT effect shows how much extra funding affects various educational outcomes if one can randomly assign school districts to the treatment and control group and prevent the schools in each group from leaving their designated group.

In order to evaluate the TOT effect of school funding on student outcome, this paper utilizes two estimation techniques. The first and main estimation technique of this paper is an extension of the dynamic regression discontinuity design, proposed by Cellini et al. (2010). In this paper their model is improved to not only account for different types of school funding, but also to have a difference-in-differences (DID) structure. The new model relies on significantly fewer assumptions compared to the original one. ${ }^{31}$ To use the terminology developed by Cellini et al. (2010), and also to distinguish my estimator from theirs, I call mine the "DID-Recursive" estimator (the original estimator is known as the "Recursive" estimator). I formally introduce this estimator later in sub section IV.B. but the general idea is explained in an example below.

Assume there are two groups of school districts that are otherwise equivalent. One group (i.e. the treatment group) receives an extra funding in year zero, while the other group (i.e. the control group) receives the same funding with a one-year delay (see Panel A of Figure 3). Assume there is no other funding available in the following years. If the effect of funding on educational outcome only depends on the number of years that has passed since the treatment (and not the calendar year that the treatment takes place) $)^{32}$, the control group follows the "same path" as the treatment group as shown in Panel A of Figure 3. In all years following the initial treatment, the usual models can only detect the difference between the treatment and control group at the end of that year (i.e. the ITT effects). However, one can construct the TOT effect for

\footnotetext{
${ }^{31}$ The identification in a difference-in-differences structure relies on the assumption that the treatment and control groups would have had the same trends in the outcome of interest if the treatment group had not received the treatment. The simple-difference model of the type suggested by Cellini et al. (2010) requires not only the trends but also the levels of the outcome of interest for the treatment and control groups to be the same in the absence of the treatment assignment.

${ }^{32}$ This is the core assumption of this estimation technique. It is a reasonable assumption in the context of school funding since there is no reason to believe that, everything else being equal, more funding in one year has a different effect comparing to other years that is not captured in the calendar year and relative year fixed effects which are included in the preferred model.
} 
a given year by adding up the ITT effects between year zero and the year of interest. Figure 3 shows, for example, how TOT $_{5}$ (i.e. TOT effect at the end of the fifth year) is constructed from ITT effects in that year and all previous years. ${ }^{33}$ Since in practice there is no guarantee that the treatment and control group share an identical pre-treatment level of the outcome variable, Panel B of Figure 3 shows how the addition of a DID structure allows for the proper identification of the TOT effect. ${ }^{34}$

[Figure 3 about here]

In our simple example, we have zero compliance in the control group and throughout this six-year period, and none of the two groups receive any additional funding beyond the one time that they receive it in year zero or one. In practice, we will account for all deviations from this simple example (the mathematical discussion is presented in sub section IV.B). Conceptually, however, the more complicated TOT estimator is nothing more than a weighted sum of these ITT effects with weights being the probability of receiving treatment in any year following the initial assignment of the school districts to treatment and control groups.

The second one is a slightly modified version of the "One-Step" estimator suggested by Cellini et al. (2010). This is simply a regression of the educational outcome on the history of school funding referenda. As it is discussed later, this estimator is biased, but other authors have mainly relied on it because of its simplicity (see for example Martorell et al., 2016). Because of that, this paper reports the results for this estimator to provide a basis to compare its findings to that of others. It is worth noting that the model is improved to account for the fact that schools may receive different types of funding as opposed to the binary case of bond referenda to build new school facilities that is being commonly studied by other authors (for example see Cellini et al. (2010), Hong, and Zimmer (2016), and Martorell et al. (2016)). I formally introduce this estimator in sub section IV.C.

For now, we limit the types of school funding to three types of operational expenditures $(\mathrm{O})$, major construction projects $(\mathrm{C})$, and smaller capital improvements and maintenance (S) to match our data on school funding referenda and also to simplify the explanation of the estimators and the mathematical equations. This methodology, however, can be easily extended to include a more detailed break-down of the types of funding that a school receives. The remainder of this

\footnotetext{
${ }^{33}$ To construct the standard error for this TOT estimator, one can rely on the delta method.

${ }^{34}$ Note that asymptotically, there is no need for this DID stricture since the pre-treatment levels would be the same if the sample size approaches the infinity.
} 
section is organized as follows: Subsection IV.A introduces the basic models that are the building blocks of the more complicated estimators used in this paper. Subsections IV.B and IV.C provide a detail description of the DID-Recursive and One-Step estimators respectively which are the two TOT estimators of this paper. Finally, subsection IV.D explains how the models can be modified to account for the heterogeneity of treatment assignment. Throughout this section, the paper generally adopts the mathematical notation developed by Cellini et al. (2010), but whenever necessary, modifications and new notations are introduced.

\section{IV.A. Basic Model}

The following equation shows a simple model that relates the outcome of interest to different types of potential treatments:

$$
Y_{j, t+\tau}=k_{\tau}+\alpha_{\tau} O_{j, t}+\beta_{\tau} C_{j, t}+\gamma_{\tau} S_{j, t}+u_{j, t+\tau} \quad \forall \tau \geq 0
$$

where $Y_{j, t+\tau}$ is an output of interest in school district $j, \tau$ years after the time of treatment assignment (i.e. $t$ ), $k_{\tau}$ is a constant term representing the average value of the outcome of interest in the schools that receive no funding, $\tau$ years after the time of treatment assignment (i.e. $t$ ), and $u_{j, t+\tau}$ is the error term. ${ }^{35} O_{j, t}, C_{j, t}$, and $S_{j, t}$ are three indicator variables associated with the type of additional expenditures authorized by the voters at time $t$ for school district $j$ and they are defined as follows: ${ }^{36}$

$O_{j, t}=1($ District $j$ approves additional operational expenditures $) \cong 1\left(v_{j, t}^{O}>v^{*}\right)$

$C_{j, t}=1$ (District $j$ approves additional major capital expenditures $) \cong 1\left(v_{j, t}^{C}>v^{*}\right)$

$S_{j, t}=1$ (District $j$ approves additional minor capital expenditures $) \cong 1\left(v_{j, t}^{S}>v^{*}\right)$

where $v_{j, t}^{O}, v_{j, t}^{C}$, and $v_{j, t}^{S}$ are the vote share in favor of approving additional operational expenditures, additional major, and minor capital expenditures, respectively. $v^{*}$ is the required

\footnotetext{
${ }^{35}$ The preferred model includes some additional control variables: A control variable for the amount of state funding allocated to the major capital projects in a school district and three indicator variables to identify the type of the proposed tax, i.e. whether it is a new tax, renewal/replacement of an existing one, or removal/reduction of an existing one.

${ }^{36}$ The use of "approximately equal" sign is to account for some practical aspects of the data. For example, assume a school district has two measures on the ballot in one period to increase its operational expenditures. Assume one of them is approved with 100 to 99 votes while the other one is rejected by 101 to 98 votes. Since one of the measures is approved, the value of $O_{j, t}$ is one, but the vote share, which we use the average values of votes for and against the measures, is less than 0.5 (i.e. 198/398).
} 
threshold vote share in favor of a type of expenditure to be considered passed. ${ }^{37}$ In Ohio, this threshold is 50 percent and any funding proposal that receives 50 percent plus one vote in favor of it is considered approved by the voters. In this framework, if the assignment of funding was random, $\alpha_{\tau}, \beta_{\tau}$, and $\gamma_{\tau}$ would be the causal effects of interest that show how much additional funding in various types of expenditures affects the outcome of interest $\tau$ years after the time of treatment assignment.

If the assignment of a school district to a treatment group was completely random, a simple OLS regression would be enough to reveal the causal effect of a specific type of funding on the outcome of interest. However, it is possible that other determinants of an educational outcome in a school district (which are all grouped in the error term in equation 14) are correlated with the vote shares (i.e. $v_{j, t}^{O}, v_{j, t}^{C}$, and $v_{j, t}^{S}$ ), and therefore correlated with the three indicator variables for the type of funding that a school district receives (i.e. $O_{j, t}, C_{j, t}$, and $S_{j, t}$ ). For example, residents of wealthy districts may spend more time and energy on the education of their children and may also be more willing to pay higher taxes to fund their schools. Therefore, a simple regression would reveal a spurious positive correlation between school funding and educational attainment, while both variables are driven by an underlying third variable, the wealth of parents. Using a simple regression in the absence of the random assignment of school funding creates biased results for the three parameters of interest (i.e. $\alpha_{\tau}, \beta_{\tau}$, and $\gamma_{\tau}$ ).

However, this is not a problematic issue if there is some exogenous variation in the vote shares (Cellini et al. 2010). For referenda that are close to the threshold vote share, one can argue that it is almost as good as a random assignment for a school district to end up on one side (and receive additional funding) or the other side (and not receive any funding). Following Cellini et al. (2010), we use a regression discontinuity technique that retains all of the referenda but also accounts for the variation that comes from the referenda not close to the threshold vote share by adding a polynomial of order $g^{38}$ in vote shares, i.e. $P_{g, \tau}\left(v_{j, t}^{O}, v_{j, t}^{C}\right)$. Theoretically, we know that:

\footnotetext{
${ }^{37}$ Any school district that fails to approve all types of additional expenditures would be considered as part of the control group. Moreover, the treatment groups are only realized after approval vote share exceeds the threshold. For example, a school district that has asked for all types of expenditures but only received approval for additional operational expenditures would be categorized as part of the treatment group that only receives operational expenditures (i.e. the values of the indicator variables for this school district would be $O_{j, t}=1, C_{j, t}=0$, and $S_{j, t}=$ $0)$.

${ }^{38}$ The preferred model of this paper uses a polynomial of order three.
} 


$$
E\left(u_{j, t+\tau} \mid v_{j, t}^{O}, v_{j, t}^{C}, v_{j, t}^{S}\right)=\lim _{g \rightarrow+\infty}\left(P_{g, \tau}\left(v_{j, t}^{O}, v_{j, t}^{C}, v_{j, t}^{S}\right)\right)
$$

So, if one defines a new error term as follows, by definition it would be independent of $v_{j, t}^{O}, v_{j, t}^{C}$, and $v_{j, t}^{S}$ (and therefore $O_{j, t}, C_{j, t}$, and $S_{j, t}$ ):

$$
\varepsilon_{j, t+\tau}=u_{j, t+\tau}-E\left(u_{j, t+\tau} \mid v_{j, t}^{O}, v_{j, t}^{C}, v_{j, t}^{S}\right)=u_{j, t+\tau}-\lim _{g \rightarrow+\infty}\left(P_{g, \tau}\left(v_{j, t}^{O}, v_{j, t}^{C}, v_{j, t}^{S}\right)\right)
$$

This means we can rewrite equation (14) as follows, and the new error term would not be correlated with the three variables of interest:

$$
Y_{j, t+\tau}=k_{\tau}+\alpha_{\tau} O_{j, t}+\beta_{\tau} C_{j, t}+\gamma_{\tau} S_{j, t}+P_{g, \tau}\left(v_{j, t}^{o}, v_{j, t}^{C}, v_{j, t}^{S}\right)+\varepsilon_{j, t+\tau} \quad \forall \tau \geq 0
$$

Equation (18) assumes that the school districts in the treatment and control groups have similar levels and trends of the outcome variable in the absence of the treatment assignment. This is a big assumption and one can significantly relax it by modifying this equation to have a differencein-differences (DID) structure. To do so, let us assume there is a pre-treatment period in which:

$$
Y_{j, t-1}=k_{-1}+\text { Treatmnet }+\varepsilon_{j, t-1}
$$

where Treatment is a $(\mathrm{J} \times 3)$ vector of indicator variables to identify the school districts that belong to the treatment group $\mathrm{O}, \mathrm{C}$, or $\mathrm{S}$ (but have not been treated yet). Combining the data from the pre-treatment period with any of the post-treatment data provides us with a DID structure as shown in the following equation:

$$
\begin{gathered}
Y_{j, t+\tau}=k_{\tau}+\text { After }+ \text { Treatment }+\alpha_{\tau} O_{j, t}+\beta_{\tau} C_{j, t}+\gamma_{\tau} S_{j, t}+P_{g, \tau}\left(v_{j, t}^{o}, v_{j, t}^{C}, v_{j, t}^{S}\right)+\varepsilon_{j, t+\tau} \\
\forall \tau \geq 0 \text { combined with } \tau=-1
\end{gathered}
$$

The new variable is After which is an indicator variable for the observations that belong to the post-treatment-assignment period. The values of $O_{j, t}, C_{j, t}$, and $S_{j, t}$ (as well as $v_{j, t}^{o}, v_{j, t}^{C}$, and $v_{j, t}^{S}$ ) are set to zero for the observations in the pre-treatment period, and as a result, $\alpha_{\tau}, \beta_{\tau}$, and $\gamma_{\tau}$ have a difference-in-differences interpretation. ${ }^{39}$ Through this simple modification, equation (20) no longer relies on the assumption that the levels of the outcome variable of interest are similar across the treatment and control group, and only assumes that the trends are the same.

\section{IV.B. DID-Recursive Estimator}

\footnotetext{
${ }^{39}$ Note that $O_{j, t}, C_{j, t}$, and $S_{j, t}$ are the same as Treatment $\times$ After that is used in the DID literature.
} 
An unbiased approach to estimating the TOT effects is to base them on the ITT effects. In this sub-section, I first show how the ITT values are estimated, and then explain how they are used to construct the TOT estimators.

We can write the ITT effect of approving a measure to increase the funding of a school district on the student outcomes $\tau$ years later as follows:

$$
Y_{j, t+\tau}=k_{\tau}+\alpha_{\tau}^{I T T} O_{j, t}+\beta_{\tau}^{I T T} C_{j, t}+\gamma_{\tau}^{I T T} S_{j, t}+P_{g, \tau}\left(v_{j, t}^{O}, v_{j, t}^{C}, v_{j, t}^{S}\right)+\varepsilon_{j, t+\tau} \quad \forall \tau \geq 0
$$

$\alpha_{\tau}^{I T T}, \beta_{\tau}^{I T T}$, and $\gamma_{\tau}^{I T T}$ are ITT estimators since we neither force the control group to not receive any type of funding in years between $t$ and $t+\tau$, nor do we keep the treated group from passing other measures to alter its funding. Note that equation (21) is exactly the same as equation (18), and by slightly modifying the notation, we are more specific about the interpretation of the parameter estimates. Therefore, we can modify it the same way we did before for equation (18) so that it has a DID structure:

$$
\begin{gathered}
Y_{j, t+\tau}=k_{\tau}+\text { After }+ \text { Treatment }+\alpha_{\tau}^{I T T} O_{j, t}+\beta_{\tau}^{I T T} C_{j, t}+\gamma_{\tau}^{I T T} S_{j, t}+P_{g, \tau}\left(v_{j, t}^{O}, v_{j, t}^{C}, v_{j, t}^{S}\right)+\varepsilon_{j, t+\tau} \\
\forall \tau \geq 0 \text { combined with } \tau=-1
\end{gathered}
$$

Note that equation (22) is also the same as equation (20). ${ }^{40}$

While $\alpha_{\tau}^{I T T}, \beta_{\tau}^{I T T}$, and $\gamma_{\tau}^{I T T}$ are unbiased in estimating the ITT effect of additional school funding on the student outcome, they are not estimated efficiently in the above equation. The error term, $\varepsilon_{j, t+\tau}$, includes unobserved covariates that are variable at the district-referendum level, but constant over time. If one pools the data used to estimate different values of $\tau$ in equation (22) to estimate all of them together, various fixed effects can be added to the model to increase precision. The new model for this pooled data is as follows:

$$
\begin{aligned}
Y_{j, t, \tau}= & k+\sum_{\tau=0}^{L}\left(\sum _ { x = 0 } ^ { L } \left\{\left[\text { After }+ \text { Treatment }+\alpha_{\tau}^{I T T} O_{j, t}+\beta_{\tau}^{I T T} C_{j, t}+\gamma_{\tau}^{I T T} S_{j, t}+\right.\right.\right. \\
& \left.\left.\left.P_{g, \tau}\left(v_{j, t}^{O}, v_{j, t}^{C}, v_{j, t}^{S}\right)\right][1(\tau=x)]\right\}\right)+\sum_{x=0}^{L} 1(\tau=x)+R_{j, t}+T_{t}+\varepsilon_{j, t, \tau}
\end{aligned}
$$

where $1(\tau=x)$ is an indicator variable identifying the data related to individual DID models that were estimated separately in equation (22) for each $\tau, R_{j, t}$ is district-referendum fixed

\footnotetext{
${ }^{40}$ Similar to equation (20), values of $O_{j, t}, C_{j, t}$, and $S_{j, t}$ (as well as $v_{j, t}^{O}, v_{j, t}^{C}$, and $v_{j, t}^{S}$ ) are set to zero for the observations in the pre-treatment period, and as a result, $\alpha_{\tau}^{I T T}, \beta_{\tau}^{I T T}$, and $\gamma_{\tau}^{I T T}$ have a DID interpretation.
} 
effects, and $T_{t}$ is the calendar year fixed effects. ${ }^{41}$ It is important to note that pooling the data in the way demonstrated in equation (23), without adding any new variables, has no effect on the parameter estimates mathematically. In other words, if one does not add the fixed effects to equation (23), the coefficients are identical to those estimated using equation (22) separately for each $\tau \geq 0$. Therefore, the fact that observations for $\tau=-1$ are repeated multiple times in the pooled data has no effect on the parameter estimates. ${ }^{42}$

Now that it is clear how ITT effects are estimated (without bias), I move on to show how this paper calculates the TOT effects. Mathematically, one can view the ITT parameters as the result of taking the total derivative of $Y_{j, t+\tau}$ with respect to $O_{j, t}$ (i.e. $\left.\alpha_{\tau}^{I T T}=\frac{d Y_{j, t+\tau}}{d O_{j, t}}\right), C_{j, t}$ (i.e. $\left.\beta_{\tau}^{I T T}=\frac{d Y_{j, t+\tau}}{d C_{j, t}}\right)$, or $S_{j, t}$ (i.e. $\gamma_{\tau}^{I T T}=\frac{d Y_{j, t+\tau}}{d S_{j, t}}$ ). Intuitively, this means that the ITT effect works through an additional operational (or capital) expenditures approved in year $t$ for the treatment group, and also through all future behaviors of treatment and control groups in approving or rejecting other measures to fund their school districts.

This total derivative can be decomposed ${ }^{43}$ into a series of partial derivatives as shown in the following equation:

$$
\begin{aligned}
& \alpha_{\tau}^{I T T}=\frac{d Y_{j, t+\tau}}{d O_{j, t}}=\left(\frac{\partial Y_{j, t+\tau}}{\partial O_{j, t}} * \frac{d O_{j, t}}{d O_{j, t}}\right)+\sum_{h=1}^{\tau}\left[\left(\frac{\partial Y_{j, t+\tau}}{\partial O_{j, t+h}} * \frac{d O_{j, t+h}}{d O_{j, t}}\right)+\left(\frac{\partial Y_{j, t+\tau}}{\partial C_{j, t+h}} * \frac{d C_{j, t+h}}{d O_{j, t}}\right)+\left(\frac{\partial Y_{j, t+\tau}}{\partial S_{j, t+h}} * \frac{d S_{j, t+h}}{d O_{j, t}}\right)\right] \\
& \beta_{\tau}^{I T T}=\frac{d Y_{j, t+\tau}}{d C_{j, t}}=\left(\frac{\partial Y_{j, t+\tau}}{\partial C_{j, t}} * \frac{d C_{j, t}}{d C_{j, t}}\right)+\sum_{h=1}^{\tau}\left[\left(\frac{\partial Y_{j, t+\tau}}{\partial O_{j, t+h}} * \frac{d O_{j, t+h}}{d C_{j, t}}\right)+\left(\frac{\partial Y_{j, t+\tau}}{\partial C_{j, t+h}} * \frac{d C_{j, t+h}}{d C_{j, t}}\right)+\left(\frac{\partial Y_{j, t+\tau}}{\partial S_{j, t+h}} * \frac{d S_{j, t+h}}{d C_{j, t}}\right)\right] \\
& \gamma_{\tau}^{I T T}=\frac{d Y_{j, t+\tau}}{d S_{j, t}}=\left(\frac{\partial Y_{j, t+\tau}}{\partial S_{j, t}} * \frac{d S_{j, t}}{d S_{j, t}}\right)+\sum_{h=1}^{\tau}\left[\left(\frac{\partial Y_{j, t+\tau}}{\partial O_{j, t+h}} * \frac{d O_{j, t+h}}{d S_{j, t}}\right)+\left(\frac{\partial Y_{j, t+\tau}}{\partial C_{j, t+h}} * \frac{d C_{j, t+h}}{d S_{j, t}}\right)+\left(\frac{\partial Y_{j, t+\tau}}{\partial S_{j, t+h}} * \frac{d S_{j, t+h}}{d S_{j, t}}\right)\right]
\end{aligned}
$$

The right-hand side variables demonstrate channels through which approving additional operational (capital) expenditures in year $t$ affects the outcome of interest in year $t+\tau$ directly, as well as indirectly through affecting the probability of approving future referenda for different

\footnotetext{
${ }^{41}$ To be precise, given the DID structure of the models, it is not necessary to pool the data in order to include these fixed effects. However, pooling the data prevents the loss of power significantly. Also note that $a f t e r \times[1(\tau=x)]$ combinations are effectively the "relative year $(\tau)$ " fixed effects.

42 The effect on standard errors is negligible.

${ }^{43}$ Recall the law of total derivative: if $Z=f(K, L)$ then $\frac{d Z}{d K}=\left(\frac{\partial f(K, L)}{\partial K} * \frac{d K}{d K}\right)+\left(\frac{\partial f(K, L)}{\partial L} * \frac{d L}{d K}\right)$
} 
types of funding and their effects on the outcome of interest in year $t+\tau$. $^{44}$ Since $O_{j, t}, C_{j, t}$, and $S_{j, t}$ are assigned in a fashion that mimics a random assignment (by focusing on the marginally passed or failed referenda), any future behavior of treatment and control groups in approving funds is a causal effect of the assignment that they receive in year $t$. Note that partial derivatives (as opposed to total derivatives) have a TOT interpretation so that the above equations could be simplified as follows:

$$
\begin{aligned}
& \alpha_{\tau}^{I T T}=\alpha_{\tau}^{T O T}+\sum_{h=1}^{\tau}\left[\left(\alpha_{\tau-h}^{T O T} * \pi_{h}^{O}\right)+\left(\beta_{\tau-h}^{T O T} * \pi_{h}^{C}\right)+\left(\gamma_{\tau-h}^{T O T} * \pi_{h}^{S}\right)\right] \\
& \beta_{\tau}^{I T T}=\beta_{\tau}^{T O T}+\sum_{h=1}^{\tau}\left[\left(\alpha_{\tau-h}^{T O T} * \varphi_{h}^{O}\right)+\left(\beta_{\tau-h}^{T O T} * \varphi_{h}^{C}\right)+\left(\gamma_{\tau-h}^{T O T} * \varphi_{h}^{S}\right)\right] \\
& \gamma_{\tau}^{I T T}=\gamma_{\tau}^{T O T}+\sum_{h=1}^{\tau}\left[\left(\alpha_{\tau-h}^{T O T} * \omega_{h}^{O}\right)+\left(\beta_{\tau-h}^{T O T} * \omega_{h}^{C}\right)+\left(\gamma_{\tau-h}^{T O T} * \omega_{h}^{S}\right)\right]
\end{aligned}
$$

where $\pi_{h}^{O}=\frac{d O_{j, t+h}}{d O_{j, t}}, \pi_{h}^{C}=\frac{d C_{j, t+h}}{d O_{j, t}}$, and $\pi_{h}^{S}=\frac{d S_{j, t+h}}{d O_{j, t}}$, represent the (intent-to-treat) effects of approving a measure to only increase operational expenditures in year $t$ on the approval of additional operational, major capital, and minor capital expenditures in year $t+h$, respectively. $\varphi_{h}^{O}=\frac{d O_{j, t+h}}{d C_{j, t}}, \varphi_{h}^{C}=\frac{d C_{j, t+h}}{d C_{j, t}}$, and $\varphi_{h}^{S}=\frac{d S_{j, t+h}}{d C_{j, t}}$ as well as $\omega_{h}^{O}=\frac{d O_{j, t+h}}{d S_{j, t}}, \omega_{h}^{C}=\frac{d C_{j, t+h}}{d S_{j, t}}$, and $\omega_{h}^{S}=$ $\frac{d S_{j, t+h}}{d S_{j, t}}$ have a very similar definition to $\pi_{h}^{O}, \pi_{h}^{C}$, and $\pi_{h}^{S}$ and the only difference is that the effects on the future referenda are measured with respect to the passage of a measure to increase the capital expenditures today. These values can be estimated using equation (23) and an appropriate left-hand side variable. ${ }^{45}$

Based on equation (25) we can find the value of the TOT estimators. First, one should note that when $\tau=0$, the ITT and TOT effects are the same since the control and treatment group do not have the time to change their treatment assignments. ${ }^{46}$ Therefore:

\footnotetext{
${ }^{44}$ The following total derivatives are assumed to be zero: $\frac{d O_{j, t}}{d C_{j, t}}, \frac{d O_{j, t}}{d S_{j, t}}, \frac{d C_{j, t}}{d O_{j, t}}, \frac{d C_{j, t}}{d S_{j, t}}, \frac{d S_{j, t}}{d O_{j, t}}$, and $\frac{d S_{j, t}}{d C_{j, t}}$. This is because the value of $O_{j, t}, C_{j, t}$, and $S_{j, t}$ are determined together and we assume that in a close referendum in which people could vote for multiple types of expenditures, the passage of one of the measures cannot affect the passage of the other ones. This is a reasonable assumption since in a close referendum people are not aware of the outcome before the votes are counted.

${ }^{45}$ In practice, the value of $O_{j, t}, C_{j, t}$, and $S_{j, t}$ are determined based on the first time that a measure appears on the ballot for school district $j$ to add additional funding for year $t$. This is to have a more conservative parameter estimate in case a school district tries to change its initial assignment to the control group (or the type of treatment) in follow up referenda for that specific year. However, the value of $O_{j, t+h}, C_{j, t+h}$, and $S_{j, t+h}$, which appear as the left-hand side variables, are determined based on the actual treatment assignment of a school district in year $t+h$. ${ }^{46}$ The existence of multiple referenda in one year, as well as the possibility to vote for future funding well-inadvance, allows for ITT and TOT at time zero to be unequal. This issue happens to about $15 \%$ of the school district-
} 


$$
\alpha_{0}^{I T T}=\alpha_{0}^{T O T}, \quad \beta_{0}^{I T T}=\beta_{0}^{T O T}, \quad \gamma_{0}^{I T T}=\gamma_{0}^{T O T}
$$

for $\tau=1$ we have:

$$
\begin{aligned}
& \alpha_{1}^{I T T}=\alpha_{1}^{T O T}+\left(\alpha_{0}^{T O T} * \pi_{1}^{O}\right)+\left(\beta_{0}^{T O T} * \pi_{1}^{C}\right)+\left(\gamma_{0}^{T O T} * \pi_{1}^{S}\right) \\
& \beta_{1}^{I T T}=\beta_{1}^{T O T}+\left(\alpha_{0}^{T O T} * \varphi_{1}^{O}\right)+\left(\beta_{0}^{T O T} * \varphi_{1}^{C}\right)+\left(\gamma_{0}^{T O T} * \varphi_{1}^{S}\right) \\
& \gamma_{1}^{I T T}=\gamma_{1}^{T O T}+\left(\alpha_{0}^{T O T} * \omega_{1}^{O}\right)+\left(\beta_{0}^{T O T} * \omega_{1}^{C}\right)+\left(\gamma_{0}^{T O T} * \omega_{1}^{S}\right)
\end{aligned}
$$

Substituting the values from equation (26) in (27) and rearranging the equations gives us:

$$
\begin{aligned}
& \alpha_{1}^{\text {TOT }}=\alpha_{1}^{I T T}-\left(\alpha_{0}^{I T T} * \pi_{1}^{O}\right)-\left(\beta_{0}^{I T T} * \pi_{1}^{C}\right)-\left(\gamma_{0}^{I T T} * \pi_{1}^{S}\right) \\
& \beta_{1}^{T O T}=\beta_{1}^{I T T}-\left(\alpha_{0}^{I T T} * \varphi_{1}^{O}\right)-\left(\beta_{0}^{I T T} * \varphi_{1}^{C}\right)-\left(\gamma_{0}^{I T T} * \varphi_{1}^{S}\right) \\
& \gamma_{1}^{T O T}=\gamma_{1}^{I T T}-\left(\alpha_{0}^{I T T} * \omega_{1}^{O}\right)-\left(\beta_{0}^{I T T} * \omega_{1}^{C}\right)-\left(\gamma_{0}^{I T T} * \omega_{1}^{S}\right)
\end{aligned}
$$

All of the right-hand side variables are ITT parameters that can be estimated using models of the form shown in equation (23).

Since we have shown how $\alpha_{1}^{T O T}, \beta_{1}^{T O T}$, and $\gamma_{1}^{T O T}$ (TOT estimators of order $\tau=1$ ) are a function of ITT estimators of order $\tau \leq 1$, we can extend this recursive technique to TOT estimators of order $\tau>1$. For example, for $\tau=2$ we can use equation (25) and rearrange it as follows:

$$
\begin{gathered}
\alpha_{2}^{\text {TOT }}=\alpha_{2}^{I T T}-\sum_{h=1}^{2}\left[\left(\alpha_{2-h}^{T O T} * \pi_{h}^{O}\right)+\left(\beta_{2-h}^{T O T} * \pi_{h}^{C}\right)+\left(\gamma_{2-h}^{T O T} * \pi_{h}^{S}\right)\right] \\
\beta_{2}^{T O T}=\beta_{2}^{I T T}-\sum_{h=1}^{2}\left[\left(\alpha_{2-h}^{T O T} * \varphi_{h}^{O}\right)+\left(\beta_{2-h}^{T O T} * \varphi_{h}^{C}\right)+\left(\gamma_{2-h}^{T O T} * \varphi_{h}^{S}\right)\right] \\
\gamma_{2}^{T O T}=\gamma_{2}^{I T T}-\sum_{h=1}^{2}\left[\left(\alpha_{2-h}^{T O T} * \omega_{h}^{O}\right)+\left(\beta_{2-h}^{T O T} * \omega_{h}^{C}\right)+\left(\gamma_{2-h}^{T O T} * \omega_{h}^{S}\right)\right]
\end{gathered}
$$

It is worth noting that all TOT parameters inside the summation are calculated in the previous steps for $\tau=0$ and $\tau=1$. Generalizing the above equations, we have the following:

$$
\alpha_{\tau}^{T O T}=\alpha_{\tau}^{I T T}-\sum_{h=1}^{\tau}\left[\left(\alpha_{\tau-h}^{T O T} * \pi_{h}^{O}\right)+\left(\beta_{\tau-h}^{T O T} * \pi_{h}^{C}\right)+\left(\gamma_{\tau-h}^{T O T} * \pi_{h}^{S}\right)\right]
$$

year combinations in our data base. For now, we ignore this issue and as a result our parameter estimates are lower bounds of the actual effect. 


$$
\begin{aligned}
& \beta_{\tau}^{T O T}=\beta_{\tau}^{I T T}-\sum_{h=1}^{\tau}\left[\left(\alpha_{\tau-h}^{T O T} * \varphi_{h}^{O}\right)+\left(\beta_{\tau-h}^{T O T} * \varphi_{h}^{C}\right)+\left(\gamma_{\tau-h}^{T O T} * \varphi_{h}^{S}\right)\right] \\
& \gamma_{\tau}^{T O T}=\gamma_{\tau}^{I T T}-\sum_{h=1}^{\tau}\left[\left(\alpha_{\tau-h}^{T O T} * \omega_{h}^{O}\right)+\left(\beta_{\tau-h}^{T O T} * \omega_{h}^{C}\right)+\left(\gamma_{\tau-h}^{T O T} * \omega_{h}^{S}\right)\right]
\end{aligned}
$$

These equations show how the TOT estimators are calculated, but one needs to estimate the standard errors for these parameters as well. This requires the application of the delta method. In order to use the delta method, the cross-model covariance matrix of coefficients in each model is required. This is an empirically easy task if instead of using four models of the form shown in equation (23) to estimate $\left\{\alpha_{\tau}^{I T T}, \beta_{\tau}^{I T T}, \gamma_{\tau}^{I T T}\right\},\left\{\pi_{\tau}^{O}, \pi_{\tau}^{C}, \pi_{\tau}^{S}\right\},\left\{\varphi_{\tau}^{O}, \varphi_{\tau}^{C}, \varphi_{\tau}^{S}\right\}$, and $\left\{\omega_{\tau}^{O}, \omega_{\tau}^{C}, \omega_{\tau}^{S}\right\}$ separately, one pools the data and estimates them all in one model. To pool four models of the type shown in equation (23), one needs to define a set of indicator variables for data related to each model and interact them with all variables (including all fixed effects). ${ }^{47}$ Similar to the previous case of pooling data, this type of pooling does not affect the parameter estimates in any way, but provides the variance-covariance matrix of all coefficients, which is a necessary input for the delta method. The estimated pooled model is the following:

$$
Y_{V, j, t, \tau}=k+\sum_{\vartheta \in V} 1(V=\vartheta)+\sum_{\vartheta \in V}\left[1(V=\vartheta)\left(E Q \cdot 23_{\vartheta}\right)\right]+\varepsilon_{V, j, t, \tau}
$$

where $Y_{V, j, t, \tau}$ is the outcome of interest of type $\mathrm{V}$ for school district $j$ in year $t$, which is measured $\tau$ years after the treatment assignment. There are four types for $\mathrm{V}$ : a student outcome (or other variables of interest), and three outcomes related to the approval or denial of additional operating, major capital, and minor capital expenditures (an indicator variable or a per pupil dollar value). $1(V=\vartheta)$ is an indicator variable that takes the value "one" if the left-hand side variable is a type $\vartheta$ outcome. EQ. $23_{\vartheta}$ is the right-hand side of equation (23) when the left-hand side variable is an outcome of type $\vartheta$. Finally, $\varepsilon_{V, j, t, \tau}$ is the error term.

\section{IV.C. One-Step Estimator}

An alternative but potentially biased method of estimating the TOT effects is to regress the outcome of interest on the history of referenda in school districts. Equation (32) shows this model: ${ }^{48}$

\footnotetext{
${ }^{47}$ These indicators should be included in the model as separate dummy variables. This is necessary to estimate the constant term of each model properly.

${ }^{48}$ For simplicity, I modify the subscript related to the time so that it is centered around the time that the outcome of interest is observed (i.e. year $t$ ).
} 


$$
\begin{aligned}
Y_{j, t}= & k+\sum_{\tau=0}^{\bar{\tau}}\left[\alpha_{\tau} O_{j, t-\tau}+\beta_{\tau} C_{j, t-\tau}+\gamma_{\tau} S_{j, t-\tau}+P_{g, \tau}\left(v_{j, t-\tau}^{O}, v_{j, t-\tau}^{C}, v_{j, t-\tau}^{S}\right)+\theta_{\tau}^{O} m_{j, t-\tau}^{O}+\right. \\
& \left.\theta_{\tau}^{C} m_{j, t-\tau}^{C}+\theta_{\tau}^{S} m_{j, t-\tau}^{S}\right]+D_{j}+T_{t}+\varepsilon_{j, t}
\end{aligned}
$$

The new variables $m_{j, t-\tau}^{O}, m_{j, t-\tau}^{C}$, and $m_{j, t-\tau}^{S}$ are indicators for the presence of referenda in school district $j$ in year $t-\tau$ to provide additional funding for operational, major capital, and minor capital expenditures, respectively. $\bar{\tau}$ is the number of past periods that are included in the history of referenda for a school district. ${ }^{49} D_{j}$ and $T_{t}$ are district and calendar year fixed effects (respectively) that account for time-invariant factors in a school district, as well as districtinvariant factors in a specific year. Note that the model allows the coefficients of the polynomial to change with the relative year (i.e. $\tau$ ). The above equation is based on the assumption that the effect of passing a measure on the outcome of interest only depends on the time that has elapsed since a referendum (i.e. $\tau$ ) and not the specific calendar year that the measure was on the ballot (i.e. t). ${ }^{50}$

If one uses a simple OLS to estimate the above model, the estimated values for variables of interest (i.e. $\alpha_{\tau}$ and $\beta_{\tau}$ ) have a treatment-on-the-treated (TOT) interpretation. This is due to the fact that OLS holds the rest of the history of referenda in a school district constant. However, this one-step estimator is biased (Cellini et al., 2010). While the error term in the above equation is not correlated with the variables (given the existence of a polynomial in vote shares), the variables may affect each other. For example, passing a referendum in year $t-1$ may affect the probability of passing another one in year $t$. This is essentially the problem of over-controlling (i.e. "bad control variables") discussed by Angrist and Pischke (2008, pp. 64-68). As they show in great detail, the inclusion of any control variable (e.g. a referendum in year $t-\tau+1$ ) that itself is an outcome of the variable of interest (e.g. a referendum in year $t-\tau$ ) biases the estimation of the coefficient of interest (e.g. $\alpha_{\tau}$ ). One should also note that this model does not allow for a DID structure to be built into it, so this model relies on more restrictive assumptions of typical one-difference models.

\footnotetext{
${ }^{49}$ In practice, one should use a large enough number that the inclusion of one more year in the past does not affect the parameter estimates for the more recent years. Specifically, I use eleven years history of school funding referenda for any given year. These eleven years include the year that the outcome of interest is measured (i.e. year "zero").

${ }^{50}$ This is a standard assumption in this literature. See Cellini et al. (2010) and Martorell et al. (2016) for two recent examples.
} 


\section{IV.D. Heterogenous Treatment Assignment}

Up to this point, the treatment groups have been defined using an indicator variable for receiving additional operational and/or capital expenditures. This simplification helped to explain the above-mentioned estimators. In practice, the amount of money received by each school district is not the same as others. One can account for this heterogeneous treatment assignment by substituting the indicator variables for the passage of an issue on the ballot (i.e. $O_{j, t}, C_{j, t}$, and $S_{j, t}$ ) with the actual per pupil dollar value of the additional funding that a school district receives. The preferred model of this paper uses per pupil expenditure in thousands of 2015 dollars for the treatment variables (i.e. $O_{j, t}, C_{j, t}$, and $S_{j, t}$ ).

An additional level of addressing the heterogeneity in treatment assignment is to use a more detailed classification of school funding instead of the three general categories (i.e. operational, minor capital, and major capital expenditures) used here. The main limitation here is the extent to which the referenda in a state have a specific language that is helpful for this purpose. In Ohio, one can clearly identify the three types of school funding referenda mentioned above.

\section{Data}

This study uses various data sources. The first and the most important one is the referendum reports from the Ohio Secretary of State Office (OSOS). ${ }^{51}$ Ohio holds state-wide referenda multiple times a year. The main ones take place on May and November of each year with some special elections on February, March, and August. The referendum reports provide the list of issues on the ballot and the number of votes for and against it. Moreover, these reports provide a brief description of each issue with all necessary information to identify the purpose of the requested funding for a school district (i.e. operational versus capital expenditures), the dollar value of the requested funding, and the period of the time that the new tax will be in place. ${ }^{52}$

\footnotetext{
${ }^{51}$ The data necessary for this study had to be extracted from these reports. Adam Isen generously shared part of the data base that he prepared for his paper and, therefore, reduced the amount of data entry for this paper. For more information about his work please see Isen (2014).

${ }^{52}$ To identify the beginning year of a new $\operatorname{tax}(\tau=0)$, this paper uses a combination of the date of referenda and the commencement year of a tax. This creates a level of heterogeneity in treatment that we ignore here. For example, assume two school districts decide to increase an identical amount of additional tax for their operational expenditures, but one of these two requests the additional funding in August 2010 and the other one in February 2011 (with commencement years being 2010 and 2011 respectively). We consider the "effective school year" for the beginning year of both taxes to be the school year 2010-11 even though these two school districts do not receive an identical amount of funding in that year. Given that planning and budgeting for a school year usually takes place before the beginning of that year, it is reasonable to assume that this additional funding in the middle of the year
} 
Section II of this paper provides year-by-year descriptive statistics of these funding proposals. Here I present an aggregated description of the referendum data that is used in this paper. ${ }^{53}$ Note that for every district-year combination, I only use the first time that a district requests extra funding in the form of additional taxes to commence in that year (if any) to identify the type of treatment assignment that it receives. For example, if a school district asks to levy a tax for a period of 5 years to begin in year 2010 in multiple referenda, the result of the first referendum is used to determine its treatment assignment. As it was mentioned before, this is to produce more conservative estimates in case some school districts in the control group (who do not receive any funding the first time they ask for it for a specific school year) were able to switch their assignment in follow up referenda before that specific school year ends. Table 2 presents the summary statistics of the aggregated data based on the purpose of the issue on the ballot. The total number of referenda for operating expenditures is slightly more than the combined number of referenda for various types of capital expenditures. On average, the size of a tax proposal to increase operational expenditures is about 3.4 times more than a proposal to increase minor capital expenditures in a year: $\$ 984.37$ and $\$ 288.87$ per pupil expenditure in 2015 dollars, respectively. Major capital expenditures have an average (life-time) size of about $\$ 10,000$ (in 2015 dollars) per pupil. Additional operating expenditures are usually approved for a shorter period of time comparing to the minor capital expenditures, 5.24 and 8.76 respectively. That being said, about 26 percent of the proposals for additional operating expenditures and 23 percent of the proposals for additional minor capital expenditures do not have a time limit and the related taxes are proposed to be collected in perpetuity. The average number of years to repay the principal and interests for the issued bonds related to major capital expenditures is about 27 years. The highest approval rate of referenda belongs to minor capital expenditures (68.60 percent), followed by operating expenditures (58.39 percent), and then major capital expenditures (45.72 percent). Finally, the percentage of close referenda in each category, defined as those with vote share between 45-55 percent, are 32.15 percent, 28.24 percent, and 37.43 percent for operating, minor capital, and major capital expenditures, respectively.

does not have an actual effect on the outcome of interest in that year. Starting with the next year $(\tau=1)$, both school districts in our example receive an identical extra funding for the whole year.

${ }^{53}$ Out of 612-613 school districts that are present in our data base for years between 1996 and 2015, we include 602 of them in our analysis. Part of the removed school districts are those that are combined or divided at some point in the years covered in this study. Other school districts share an entity (i.e. Lake County School Financing District) that has the power to levy taxes to fund schools, and just to be sure about the proper allocation of raised funds to school districts, we remove these districts from the data base as well. 
[Table 2 about here]

Figure 4 shows the distribution of vote share in favor of measures to receive additional funding for operational (Panel A) minor capital, and major capital expenditures (Panels B and C, respectively). It is worth nothing that the bell-shape of the vote distribution in both panels, as well as the similarity of the number of measures that are marginally rejected or approved, provides us with more confidence in our identification technique that relies on the randomness of the treatment assignment for schools that are close to the 50 percent vote margin.

[Figure 4 about here]

The second main data base used in this study is the results of the math proficiency tests for students subject to high school graduation tests. Prior to the school year 2005-06, the proficiency in $9^{\text {th }}$ grade core courses ${ }^{54}$ was required for graduation. Starting in the school year 2005-06, the Ohio Graduation Test was introduced and required proficiency in $10^{\text {th }}$ grade core courses. The high school graduation math proficiency data covers school years from 1996-97 to 2014-15. ${ }^{55}$ Figure 5 shows the school district average proficiency rates in math. Average math proficiency rates for Ohio appear to be constant over time for each grade but increase by about 10 percent between grades 9 and 10. The standard deviation also decreases for $10^{\text {th }}$ graders. In earlier years, the value of standard deviation is about 13 percent, while in later years, it reduces to about 8 percent. We normalize the math proficiency rates of a school district in each year to account for the fact that the test may have changed from one year to another and also, they are administered to students of different grades over this period of time.

[Figure 5 about here]

Other important district level variables that this paper looks at are the district level total per pupil expenditures, average expenditures on instructional staff, student to teacher ratio (all available through NCES), attendance rate, and disciplinary actions per 100 students (all available through ODE). These variables are available for different school years and Table 3 provides summary statistics for these variables for the school districts included in this study. First, one should note the variation in the size of school districts that are included in this analysis. While

\footnotetext{
${ }^{54}$ Proficiency in five subject areas is required for graduation: mathematics, writing, reading, science and social studies. The subject areas did not change in 2006.

${ }^{55}$ David Brasington very generously shared his data for 1996-97 to 2004-05 period with us. For the application of this data in his work see, for example, Brasington and Haurin (2009). His data base uses $8^{\text {th }}$ graders math proficiency rates for the academic year 2004-05 because of the lack of data on $9^{\text {th }}$ and $10^{\text {th }}$ graders. The data for 2005-06 forward is available through ODE website.
} 
the average and median number of students in a school district are about 2,850 and 1,787 respectively, there are school districts that serve as few as 67 and as large as 76,504 students. The average per pupil expenditures in 2015 dollars is about 12 thousand dollars with a standard deviation of 4 thousand dollars. The average expenditure on instructional staff (in 2015 dollars) is about 96 thousand dollars with a standard deviation of about 14 thousand dollars. For both variables, there is great variation across school and over time for the size of these two expenditure variables. The average number of students per teacher is about 17. The variable ranges from only 4 students to 54 students per teacher. Attendance rate is the variable with the least range. Over the past decade, Ohio school districts experienced between 89 percent to 98 percent attendance rate, amounting to an average of 96 percent. Finally, the number of disciplinary actions per 100 students is most likely the variable with the most variation in this table. From 0 to 261 disciplinary actions per 100 students, school districts in Ohio are very different in terms of the type of students that they serve. The average and median values, however, are about 16 and 10 actions per 100 students respectively, which shows most of school districts do not experience that much trouble with their students.

[Table 3 about here]

Before moving forward, it is necessary to examine whether the school districts that succeed in securing various types of additional funding (the treatment groups) and those who fail to do so (the control group) are otherwise similar. Specifically, one needs to test whether the treatment and control groups are balanced with respect to various outcome variables before they receive the extra funding. Since the DID-Recursive estimator has a difference-in-differences structure, we are less worried about the balance in levels of the outcome variables across treatment and control groups prior to the treatment assignment, and only need to establish a similar pretreatment trend in these variables.

Table 4 provides the results of the pre-treatment balance test for the trends of various outcome variables. The regression models used for Panel A and B are only different in one set of variables: only the model used for Panel B includes polynomials (of order three) in vote shares (i.e. three polynomials since there are three types of referenda depending on the type of additional expenditure proposed in a referenda). All models regress an outcome of interest measured before a referendum is proposed (I include up to three years before a referendum) on set of variables related to that referendum. These variables are as follows: three variables for the 
type of per pupil expenditures (in thousands of 2015 dollars) proposed (i.e. operating, minor capital, and major capital expenditures); a relative time trend variable, Tao, that takes values -3 , -2 , and -1 depending on the year that the outcome of interest is measured relative to the year of a referendum (e.g. -1 means the outcome of interest is measured one year before a referendum); three interaction terms between Tao and the three variables mentioned previously (these interaction terms are the main variables of interest and reported in the Table 4); a control variable for the state-provided additional funding for major capital projects; three indicator variables to identify the type of the proposed tax (i.e. whether it is a new tax, renewal/replacement of an existing one, or removal/reduction of an existing one); and finally, school district and calendar year fixed effects.

\section{[Table 4 about here]}

As the parameter estimates in Table 4 Panel A reveal, even without the inclusion of the vote share polynomials, the treatment and control groups have a similar trend with regard to most of the outcome variables. Those few cases in which a treatment group appears to have a differential trend compared to the control group, the inclusion of the vote share polynomials takes care of these differential trends as depicted in Panel B. Parameter estimates presented in this panel provides the necessary evidence that shows once polynomials of order three in vote shares are included in the model, treatment and control groups have very similar trends in the main outcomes of interest prior to the treatment assignment.

\section{Results}

Before presenting the main results, it is important to examine how approving various types of additional funding affects the total expenditure in a school district. Figure 6 shows these effects for 10 years following a reform in three graphs using simple ITT models of the form shown in equation (22). Panel A shows that approving an additional operating expenditure (measured in per pupil thousands of 2015 dollars per year) increases the total per pupil expenditure for slightly less than the approved size of a referenda (about 24 percent less), and the effect remains relatively constant over time. Panel B shows that approving additional funding for minor capital projects (measured in per pupil thousands of 2015 dollars per year) leads to an increase in the total per pupil expenditure that exceeds the size of the reform (about 47 percent more). This is expected, as school districts may combine available funds through State and Federal government for renovation with the funding that they receive through additional local 
taxes. Panel $\mathrm{C}$ shows that approving an additional $\$ 1,000$ for a major capital project (measured in 2015 dollars) leads to an additional total per pupil expenditure close to the approved extra funding over the course of five years following the reform (i.e. year zero through four, in which year zero is the year of commencement for an approved additional tax). ${ }^{56}$ Overall, these graphs show that the approval of additional taxes by voters leads to a real increase of a similar size in total school expenditures.

[Figure 6 about here]

Table 5 illustrates the main result of this paper. It shows how approving various types of school expenditures affects the school district level math proficiency rates of students who take Ohio high school graduation tests. The main variables of interest are the size of the approved additional funding for various purposes, which are measured in per pupil thousand of 2015 dollars (per year for operating and minor capital expenditures and per project for major capital expenditures). Across various panels, I find a short-term effect for additional operating expenditures, but not for any types of capital expenditures. The preferred results are presented in Panel B, which shows that for every $\$ 1,000$ (constant-2015) additional yearly per pupil expenditure approved by the voters for operating expenses, the math proficiency rate of students increases by about 0.033 standard deviations ( 0.27 percentage points) one year following the commencement of the new tax. The effect size is not significant for year zero, as well as two through four, but the parameter estimate has a similar size. The effect goes away in the fifth year following the referenda. Both Panel C (which uses a simpler but biased estimator of the TOT effect) and Panel A (which shows the ITT effects) display a very similar pattern in which the effect of additional funding is reduced significantly by the fifth year following a referendum.

[Table 5 about here]

Despite the fact that the parameter estimates for both types of capital expenditures are statistically insignificant, it is worth noting that the major capital expenditures seem to have a consistent negative effect on test scores for at least the first six years included in this analysis. One may argue that the major capital projects takes a few years to be completed and one should not expect any positive effect until later years. Moreover, the fact that a school's administration is occupied with a major construction project provides potential explanation for a short term

\footnotetext{
${ }^{56}$ Note that this effect comes solely from the local sources since the availability of data allows the model to control for the additional matching fund that a school district receives from the State for its major capital projects.
} 
negative effect (e.g. through the reduction in supervision). To assess whether the effect of building a school on test scores appear in later years, I expand the time horizon of the analysis to include up to 10 years following the commencement year of a referendum. To better visualize the result, Figure 7 presents the effect of approving a major capital project (measured in per pupil thousands of constant-2015 dollars) on the students test scores. As it is clear from this Figure, the effect is never positive and mainly statistically insignificant. Therefore, one can conclude that this paper does not find any evidence for short-term or long-term effects of major capital expenditures on educational outcome of students.

[Figure 7 about here]

The next step is to analyze various channels through which the additional funding for school districts can affect student achievement. This paper looks at four channels: student to teacher ratio, student attendance rate, prevalence of disciplinary actions, and average expenditure on instructional staff. Table 6 presents the results of this analysis. With the exception of the average expenditure on instructional staff, none of the other channels show any potential in explaining the relationship between the extra funding for schools and test scores. Results in Panel D of Table 6 show that the approval of a new tax to spend an additional $\$ 1,000$ (in 2015 dollars) per pupil operating expenditure leads to an average of \$292 (in 2015 dollars) extra expenditure (although statistically insignificant) on the instructional staff one year following the commencement of the new tax. This effect increases dramatically in the second year following the commencement of the new tax to $\$ 830$ (in 2015 dollars) and it becomes statistically significant. The effect continues to rise in the following years and reaches \$1856 (in 2015 dollars) in the fifth year following the commencement of a new tax. It is important to note that the effect on the average expenditure on instructional staff increases over time, but the effect on test scores only appears in a short period following the commencement of a new tax (see Panel B in Table 5). This is an indication that the passage of such a referendum creates a short-term increase in the motivation of teachers. This could be a short term financial or non-financial motivation. Teachers may initially notice that their salaries and benefits has increased and became more motivated in their work but then this extra earning becomes less noticeable over time. The non-financial motivation can come from, for example, the good feeling that teachers may have when their community votes in favor of a measure that will lead to an increase in their 
salary. The feeling that voters appreciate their work may lead to an initial increase in their efforts but over time, this type of motivation loses its effect.

[Table 6 about here]

While the above explanation seems plausible for the referenda related to the additional operating expenditures, it is important to examine why the referenda related to minor capital expenditures do not seem to have a similar impact on test scores. Panel D of Table 6 reveals that this type of referendum increases the average expenditures on the instructional staff even more than the referenda passed to increase operating expenditures. The key to resolving this puzzle is to notice the standard errors in Panel D of Table 6 and Panel B of Table 5. In both tables, the standard errors are much larger for the case of referenda to increase minor capital expenditures. Additional minor capital expenditures approved by the voters may lead to some of the schools moving the money around and increasing the salary and benefits of the instructional staff. However, not every school district could or would do this, which one can infer from the size of standard errors in Panel D of Table 6 (comparing values in the row for operating expenditures to the ones for minor capital expenditure). If there is a higher variation in the number of schools that redirect part of the new resources to be spent on the instructional staff, the effect on the student test scores would have a higher variation as well, resulting in higher values for standard errors in Panel B of Table 5. Therefore, the results in Tables 5 and 6 are fully consistent with the explanation offered earlier for how the approval of additional funding for school districts affects the student test scores through the increase in the expenditure on the instructional staff.

The next step is to test the robustness of the main results of paper (i.e. the effect of approving various types of additional funding for schools on test scores). Here I offer two robustness checks and a set of pseudo regressions that are presented in Tables 7 and 8 , respectively. First, the whole analysis is repeated for the reading proficiency rate of the students who are subject to the Ohio high school graduation tests ${ }^{57}$ and the results are presented in Panel A of Table 7. The approval of additional operating expenditure increases the reading proficiency very similar to the math proficiency examined before. The effect is statistically significant for the first and second years following the commencement of a new tax, increasing the proficiency rate for reading by about 0.047 and 0.063 standard deviations ( 0.56 and 0.69 percentage points) for every $\$ 1,000$ (constant-2015) additional yearly per pupil expenditure approved by the voters,

\footnotetext{
${ }^{57}$ The data for this test score is available for years 2005 to 2014 .
} 
respectively. The effect becomes statistically insignificant for the third and fourth years and disappears in the fifth year following the commencement year of a new tax. The effect from minor capital expenditures is generally statistically insignificant (similar to the results for math proficiency) while the parameter estimates are positive and of similar size as the ones observed for the operating expenditures. In line with the previous findings, the major capital expenditures have a negative but statistically insignificant effect on the reading proficiency rates.

[Table 7 about here]

For the second robustness check, the same model as the one used for our main results (i.e. table 5) is used, but the data is limited to only close referenda (i.e. the ones with 45 percent to 55 percent vote share). The effect for the approval of operating expenditures is larger and statistically significant for both the commencement year and the first year following it: respectively about 0.046 and 0.062 standard deviations ( 0.35 and 0.48 percentage points) increase in math proficiency rates for every $\$ 1,000$ (constant-2015) additional yearly per pupil expenditure approved by the voters. A very similar pattern as before is observed for both minor and major capital expenditures, but the negative effect of major capital expenditures on test scores becomes statistically significant in some years: a reduction of about 0.011 to 0.019 standard deviations ( 0.20 to 0.24 percentage points) in math proficiency rate for every $\$ 1,000$ (constant-2015) additional per pupil expenditure on a major capital project approved by the voters.

Table 8 presents the results of the pseudo regressions in which I analyze the effect of future referenda on a range of variables in the past. One would expect that the approval of additional funding for any of the three purposes in the future would not have any effect on the important variables of interest in the past. To do these pseudo regressions, this paper uses a simple DID model using only two periods before the commencement of a new tax, i.e. $\tau=-2$ the pretreatment period and $\tau=-1$ the (pseudo) posttreatment period. The structure of model and the included covariates are very similar to the equation (22). As Table 8 shows, there is no evidence that future new taxes have any effect on the level of math proficiency rate, total per pupil expenditure, average expenditure on instructional staff, student-teacher ratio, student attendance rate, and prevalence of disciplinary actions in previous years.

[Table 8 about here] 
The last step in the analysis of the effect of extra funding on schools is to see what type of students benefit more from. Specifically, it is important to see whether poor students benefit more than rich students from additional funding for their schools. The nature of data used in this paper does not allow a direct assessment of the impact of additional funding on these two groups of students. The next best option is to look at the school districts in places with high and low poverty rates among children and assess whether there is any differential effect. To do so, I use the school district level poverty rates among children estimated by Census (2017) for year 1995 to rank the school districts. Then I split the data to only include school districts with poverty rates in the top 30 percent ("poor school districts") in one subsample and the ones with poverty rates in the bottom 30 percent ("rich school districts") in another subsample. The rest of the analysis is identical to the one done for the main results (i.e. Table 5) but with these two data bases used separately in the estimations. The results are shown in Table 9. It is very clear that the poor school districts drive the results for the effect of operating expenditures on math proficiency rates. While the effect of additional operating funding for rich school districts is small and statistically insignificant, the poor school districts experience effects as large as 0.123 standard deviations (about 1.98 percentage points) ${ }^{58}$ increase in math proficiency rates in the first year following the commencement year of a tax. This effect remains relatively stable for up to four years following the commencement year and then is reduced significantly in the fifth year. ${ }^{59} \mathrm{On}$ the other hand, the negative effect of major capital projects on math proficiency rates that was observed before seems to be driven by the rich school districts. The effect becomes statistically significant in the second year following the commencement of a new tax to pay for the new bonds issued to pay for a major project: Every additional \$1,000 (constant-2015) approved to be spent on a major project decreases the math proficiency rates in rich school districts by about 0.007 standard deviations (about 0.10 percentage points). The effect becomes even stronger in the fourth and fifth year: a reduction of about 0.013 and 0.008 standard deviations (about 0.18 and 0.13 percentage points), respectively.

[Table 9 about here]

\footnotetext{
${ }^{58}$ This effect is for every $\$ 1,000$ (constant-2015) additional yearly per pupil operating expenditure approved by the voters.

${ }^{59}$ The parameter estimates are not all statistically significant.
} 


\section{Conclusions}

This paper analyzes the roles of various types of public school expenditures on test scores of students in Ohio. Specifically, it compares the impact of operating versus minor capital versus major capital expenditures on the math proficiency rate of students who are subject to Ohio high school graduation tests. Moreover, this paper examines four channels (i.e. student-to-teacher ratio, student attendance rate, disciplinary actions per 100 students, and average expenditure on instructional staff) through which the additional expenditures in either of these three categories could potentially affect the performance of students.

The preferred model shows a positive and statistically significant effect of the operating expenditures on the math proficiency rates in the short run, i.e. 0.033 standard deviations $(0.27$ percentage points) in the first year following the commencement year of a new tax for an additional \$1,000 contant-2015 per pupil operating expenditure. However, I do not find any long-term effect for the additional operating expenditures or any effect (neither short-term nor long-term) for both types of capital expenditures. The additional funding in these three categories has no economically significant impact on the class size (student-to-teacher ratio), attendance rate, or discipline of students. However, the average expenditure on instructional staff increases with the approval of additional operating expenditures, indicating that incentives of the teachers is a main channel through which the test score of students can be affected. Finally, this paper provides evidence that the extra operating expenditure has a much higher effect (4 to 9 times higher than average effect) on schools that are located in relatively poor districts.

The results of this study encourage policy makers in charge of public education at the state and federal level to focus their limited resources on areas that have an actual effect on students' achievements. The fact that various studies, including this one, have not been able to identify any effect for major capital expenditures on student outcomes suggests that much less financial resources at the state and federal level should be allocated to construction projects. On the other hand, this paper shows that spending on teachers is an effective way to increase test scores, especially in the school districts that serve students from lower socioeconomic status. Therefore, policies that aim at increasing the quality of teachers, for example through equalizing the financial power of schools to hire and compensate high quality teachers, are the most promising ones to affect the educational achievement of students. 
Future studies should focus their attention on other channels that additional funding can affect student outcomes (such as college preparation courses or extracurricular activities) and specifically the ones that have the most effect on the students of lower socioeconomic status. An important limitation of this study is the lack of access to the student-level data which prevents conducting such an analysis. However, future work can overcome this limitation, as state officials are becoming more open to allowing researchers to access such data. Finally, it is worth noting that the methodology of this paper can be utilized in other contexts, for example, to study the effect of various types of referenda to increase taxes on housing prices or the number of new businesses. This is a natural extension of existing studies on these topics (see for example Cellini et al., 2010; Reynolds and Rohlin, 2017).

\section{References}

Angrist, Joshua D., and Jörn-Steffen Pischke. "Mostly harmless econometrics: An empiricist's companion. " Princeton university press, 2008.

Becker, Gary S. "Human Capital: A Theoretical and Empirical Analysis, with Special Reference to Education." University of Chicago Press, 1964.

Brasington, David M., and Donald R. Haurin. "Parents, peers, or school inputs: Which components of school outcomes are capitalized into house value?." Regional Science and Urban Economics 39, no. 5 (2009): 523-529.

Breen, Richard. "Educational expansion and social mobility in the 20th century." Social Forces 89, no. 2 (2010): 365-388.

Brown, Phillip. "Education, opportunity and the prospects for social mobility." British Journal of Sociology of Education 34, no. 5-6 (2013): 678-700.

Card, David, and Alan B. Krueger. "School Resources and Student Outcomes: An Overview of the Literature and New Evidence from North and South Carolina." The Journal of Economic Perspectives 10, no. 4 (1996): 31-50.

Cellini, Stephanie Riegg, Fernando Ferreira, and Jesse Rothstein. "The value of school facility investments: Evidence from a dynamic regression discontinuity design." Quarterly Journal of Economics 125, no. 1 (2010).

Coleman, James S. et al. "Equality of Educational Opportunity." National Center for Educational Statistics, document number: ED012275. (1966). Available at: $\underline{\text { http://eric.ed.gov/?id=ED012275 }}$

Census, 2017. Small Area Income and Poverty Estimates: School District Data Files. data Extracted in July 2017. Available at: https://www.census.gov/did/www/saipe/data/schools/data/index.html

Duflo, Esther. "Schooling and Labor Market Consequences of School Construction in Indonesia: Evidence from an Unusual Policy Experiment." American Economic Review 91, no. 4 (2001): 795813.

Fryer, Roland G. "Teacher incentives and student achievement: Evidence from New York City public schools." Journal of Labor Economics 31, no. 2 (2013): 373-407.

Greenwald, Rob, Larry V. Hedges, and Richard D. Laine. "The effect of school resources on student achievement." Review of educational research 66, no. 3 (1996): 361-396.

Goldin, Claudia Dale, and Lawrence F. Katz. "The race between education and technology." Harvard University Press, 2009. 
Hedges, Larry V., Richard D. Laine, and Rob Greenwald. "An exchange: Part I: Does money matter? A meta-analysis of studies of the effects of differential school inputs on student outcomes." Educational researcher 23, no. 3 (1994): 5-14.

Hanushek, Eric A. "The economics of schooling: Production and efficiency in public schools." Journal of economic literature 24, no. 3 (1986): 1141-1177.

Hanushek, Eric A. "An exchange: Part II: Money might matter somewhere: A response to Hedges, Laine, and Greenwald." Educational Researcher 23, no. 4 (1994): 5-8.

Hong, Kai, and Ron Zimmer. "Does Investing in School Capital Infrastructure Improve Student Achievement?." Economics of Education Review 53 (2016): 143-158.

Hong, Kai, School Bond Referendum, Capital Expenditure, and Student Achievement (December 16, 2016). NYU Wagner Research Paper No. 2886666. Available at SSRN: https://ssrn.com/abstract=2886666 or http://dx.doi.org/10.2139/ssrn.2886666

Isen, Adam. "Do local government fiscal spillovers exist? Evidence from counties, municipalities, and school districts." Journal of Public Economics 110 (2014): 57-73.

Jackson, C. Kirabo, Rucker C. Johnson, and Claudia Persico. "The Effects of School Spending on Educational and Economic Outcomes: Evidence from School Finance Reforms." The Quarterly Journal of Economics 131, no. 1 (2016): 157-218.

Jennings, Jack. "Reflections on a Half-Century of School Reform: Why Have We Fallen Short and Where Do We Go from Here?." Center on Education Policy (2012).

Kogan Vladimir, Stephane Lavertu, and Zachary Peskowitz. "School District Tax Referenda, Spending Cuts, and Student Achievement." Working paper, February (2016). Available at: https://aefpweb.org/sites/default/files/webform/41/KLP RDlevy 02172016.pdf

Lavertu, Stéphane, and Travis St. Clair. "Beyond Spending Levels: School District Revenue Uncertainty and Student Achievement.", AEFP 42nd Annual Conference, March 16-18 (2017). Available at: https://aefpweb.org/sites/default/files/webform/42/LavertuStClair 20170116.pdf

Martorell, Paco, Kevin Stange, and Isaac McFarlin. "Investing in schools: Capital spending, facility conditions, and student achievement." Journal of Public Economics (2016).

NCES: National Center for Education Statistics, U.S. Department of Education. Common Core of Data (CCD). Data extracted in February 2017. https://nces.ed.gov/ccd/elsi/tableGenerator.aspx

Neilson, Christopher A., and Seth D. Zimmerman. "The effect of school construction on test scores, school enrollment, and home prices." Journal of Public Economics 120 (2014): 18-31.

ODE: Ohio Department of Education. Information and data Extracted in February 2017. http://bireports.education.ohio.gov http://education.ohio.gov/Topics/Finance-and-Funding/SchoolPayment-Reports/State-Funding-For-Schools/Traditional-Public-School-Funding

ODT: Ohio Department of Taxation. Information and data extracted in February 2017. http://www.tax.ohio.gov/tax analysis/tax data series/school district data/publications tds school.a spx http://www.tax.ohio.gov/school district income.aspx

OFCC: Ohio Facilities Construction Commission. Information and data Extracted in February 2017. http://ofcc.ohio.gov/ServicesPrograms/K-12Schools/CFAP.aspx http://ofcc.ohio.gov/Resources/Publications.aspx\#115657-annual-reports http://ofcc.ohio.gov/NewsEvents/NewsReleases/20120712.aspx

OSOS: Ohio Secretary of State. Information extracted in February 2017. https://www.sos.state.oh.us/SOS/Upload/elections/EOresources/general/2013QandI.pdf

Pittner, Nicholas A., Melissa M. Carleton, and Cassandra Casto. "School funding in Ohio: From DeRolph to the evidence-based model (EBM) and beyond." journal of education finance 36, no. 2 (2010): 111142.

Reynolds, C. Lockwood, and Shawn M. Rohlin. "Property Taxation and Businesses: A Regression Discontinuity Approach", AEFP 42nd Annual Conference, March 16-18 (2017). Available at: https://aefpweb.org/sites/default/files/webform/42/Property $\% 20$ Taxation $\% 20$ and $\% 20$ Businesses $\% 20$ $\underline{-\% 20 \text { AEFP.pdf }}$ 
Figure 1: Capital expenditure and spending on the instructional staff in Ohio vs. the United States as a share of total expenditure.

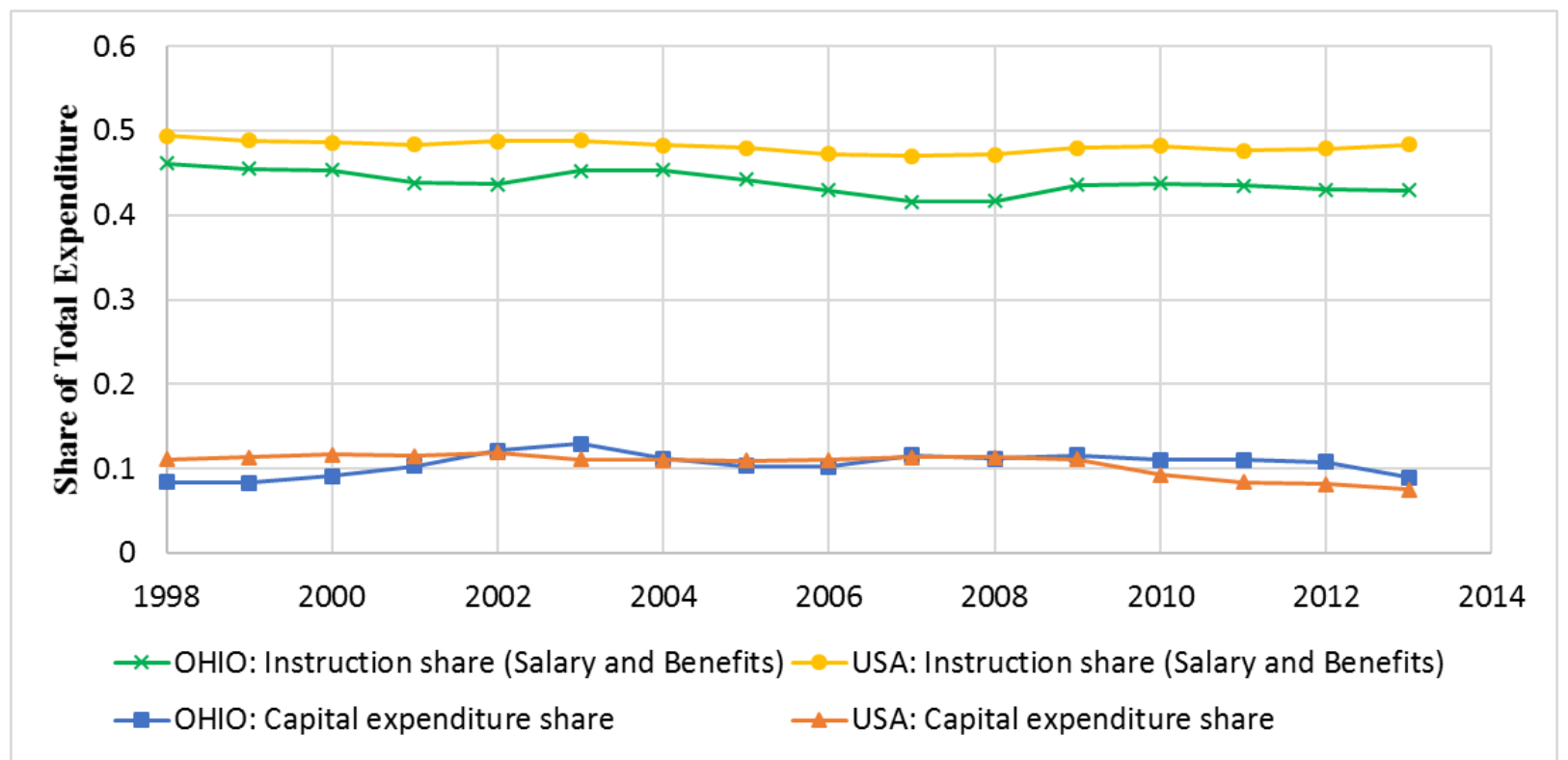

Source: U.S. Department of Education, National Center for Education Statistics, Common Core of Data (CCD) and own calculations.

Figure 2: Share of school budget financed through the local sources.

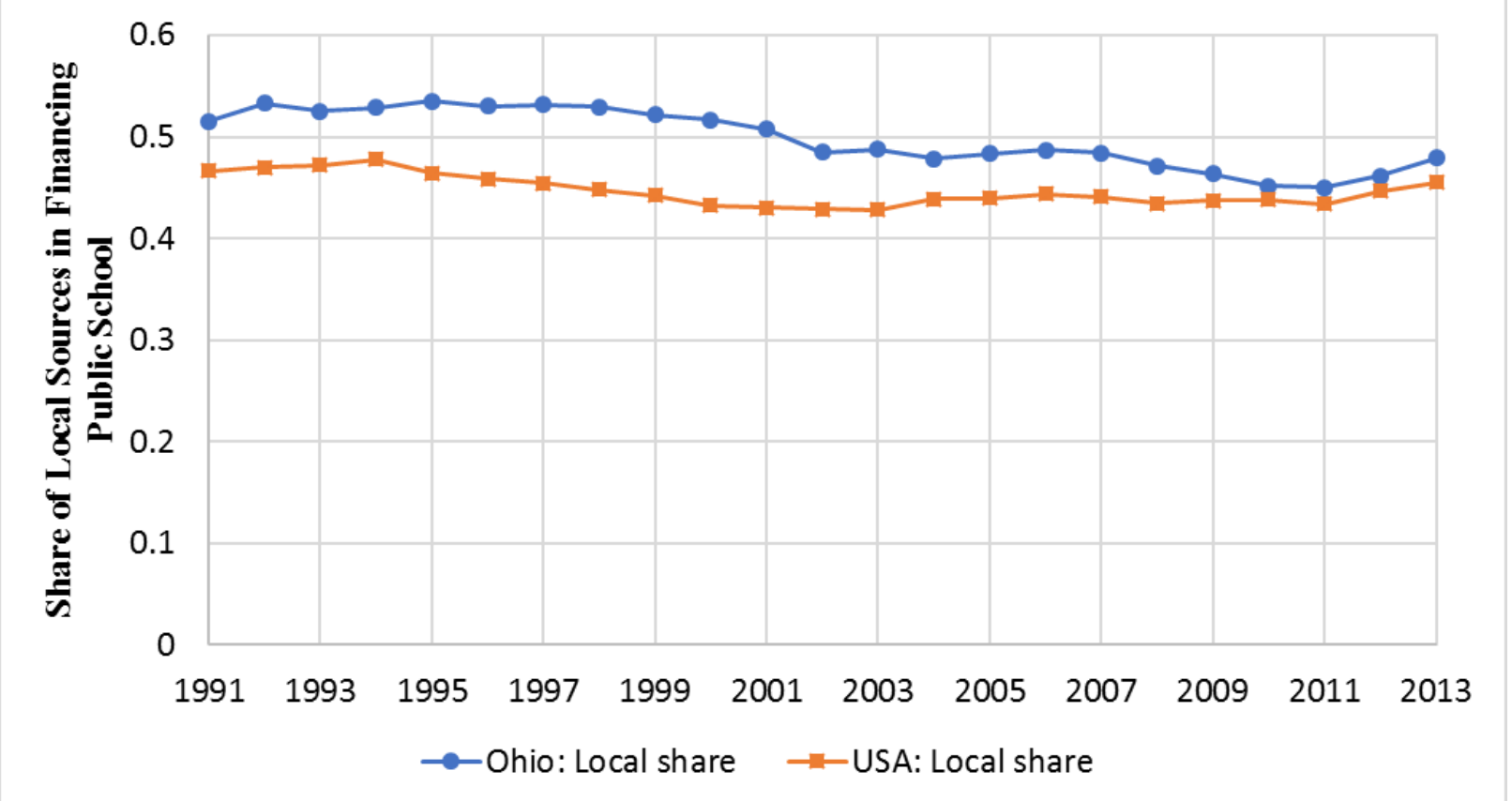

Source: U.S. Department of Education, National Center for Education Statistics, Common Core of Data (CCD) and own calculations. 
Figure 3: The relationship between the Treatment-on-the-Treated (TOT) estimator and the Intent-to-Treat (ITT) estimators.

Panel A) Without the Need for a Difference-in-Differences Structure

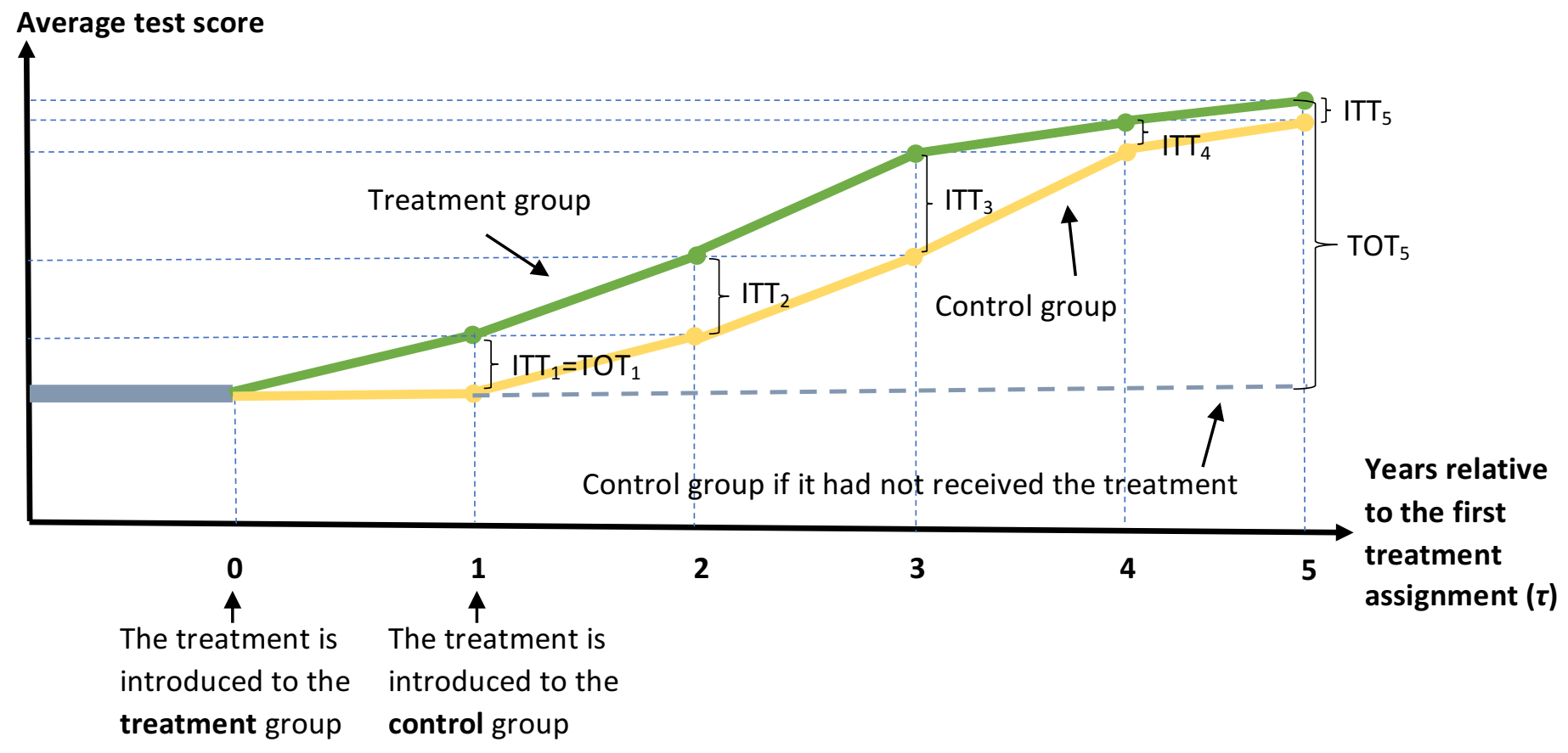

\section{Panel B) With a Need for a Difference-in-Differences Structure}

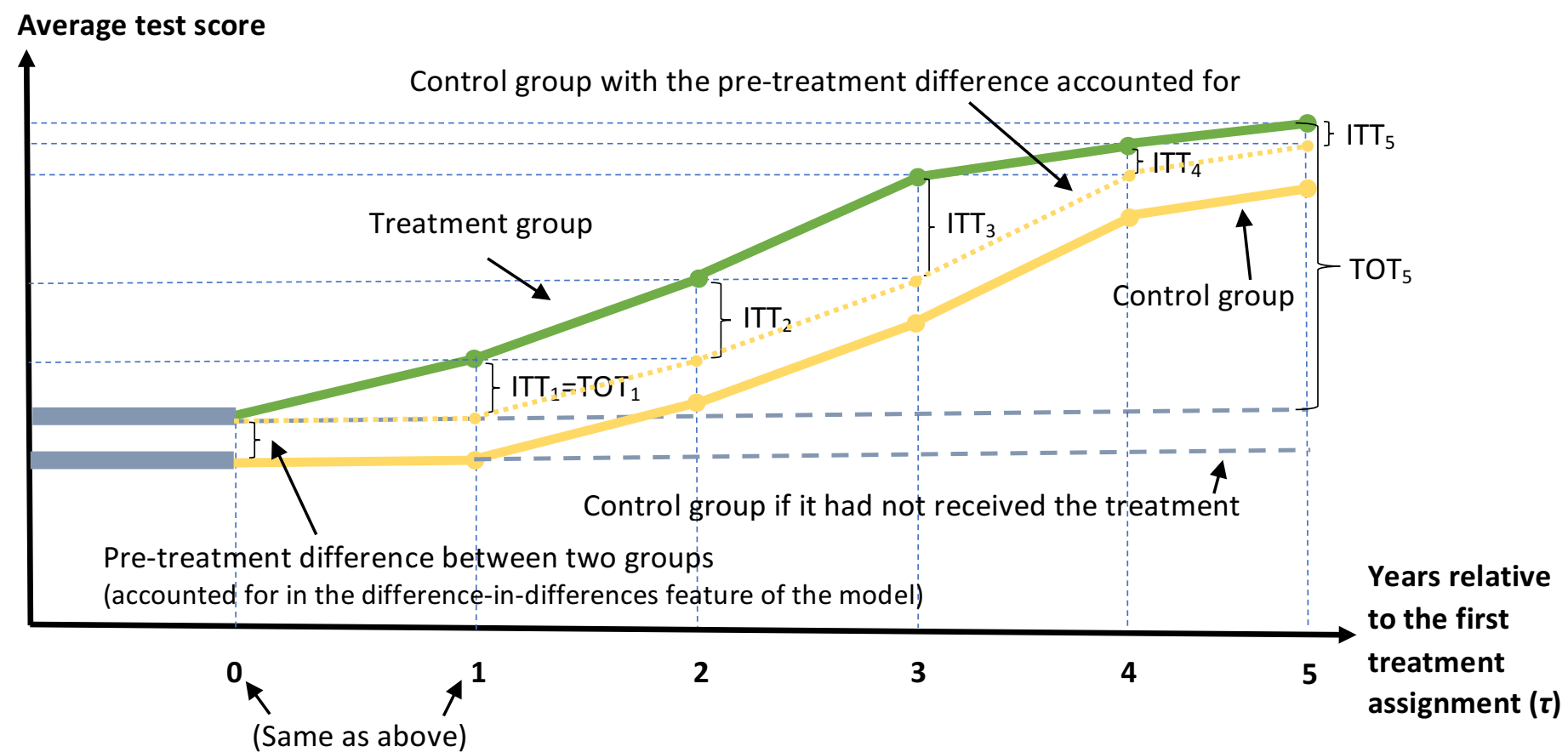

Note: The treatment-on-the-treated (TOT) estimator in the long run is equal to the sum of intent-to-treat (ITT) estimators (assuming the control group receives a similar treatment and it is otherwise similar to the treatment group). 
Figure 4: Distribution of vote share in favor of measures to spend more operational and capital expenditures.
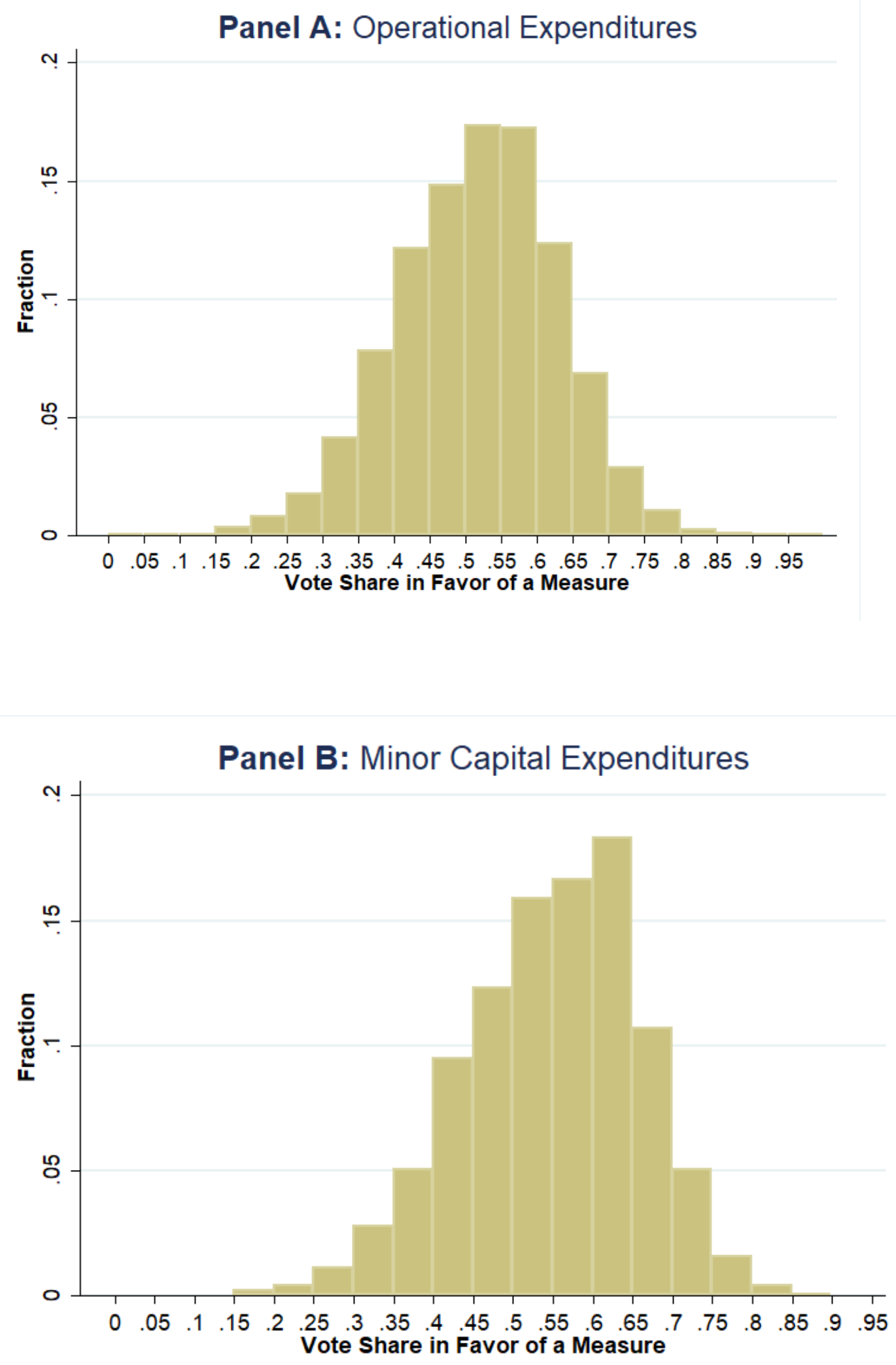


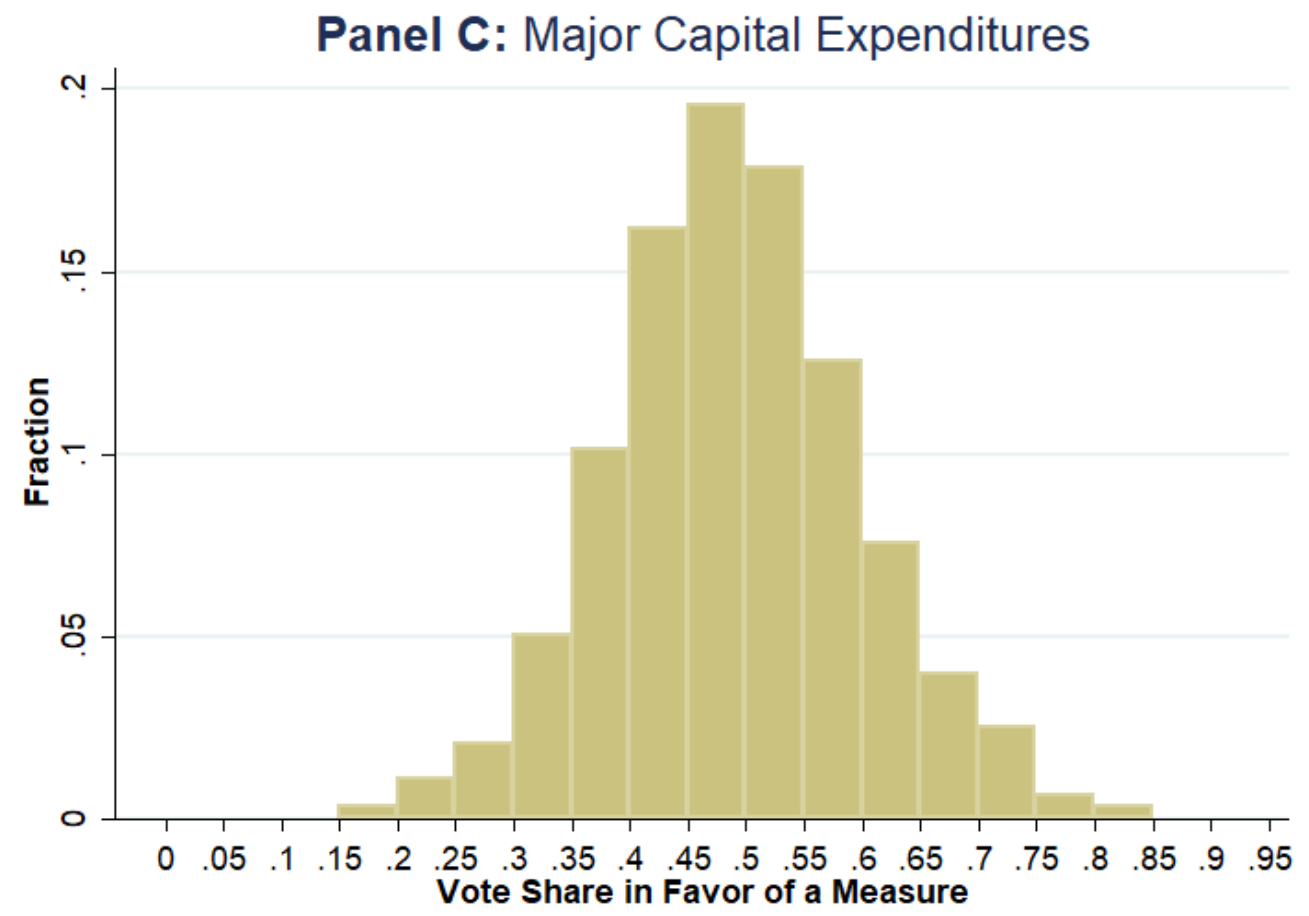

Sources: Referendum reports from the OSOS and own calculations.

Notes: The data covers years from 1996 to 2015 for 602 Ohio school districts included in this paper. Only referenda related to the first time a school district requested additional funding in the form of a new tax to be commenced in a specific year are included. The total number of referenda included in Panels A, B, and C are 3350, 1452, and 1074 respectively. 
Figure 5: Average math proficiency rate of school districts in Ohio for students subject to the high school graduation requirement.

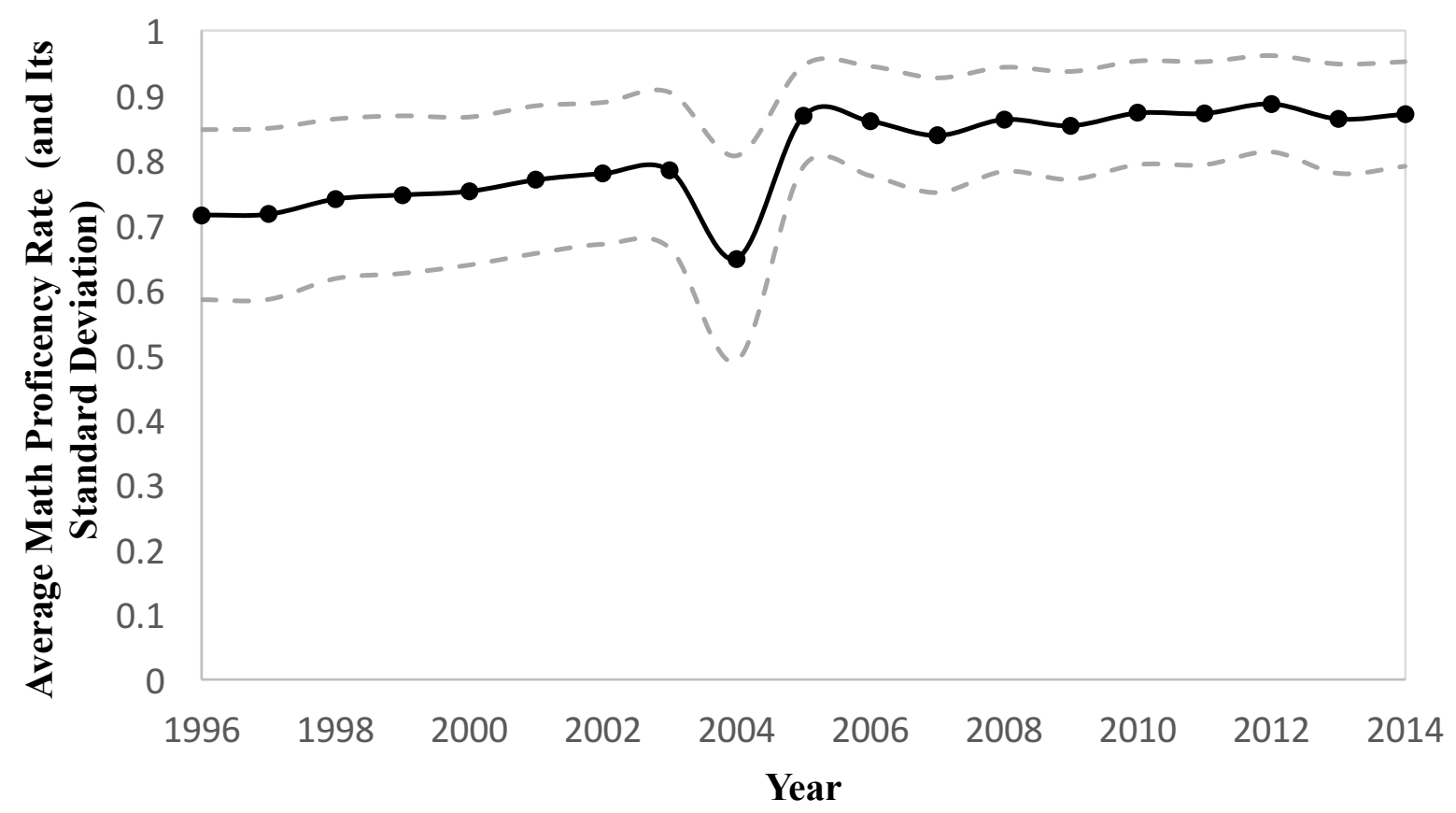

Sources: David Brasington personal data base (1996-2004), ODE (2005-2014), and own calculations.

Notes: The data includes 602 Ohio school districts included in this paper. The year corresponds to the Fall semester of a school year. The dotted line displays the standard deviation. Math proficiency rates for 1996-2003 is for $9^{\text {th }}$ graders, 2004 is for $8^{\text {th }}$ graders (due to the absence of data for $9^{\text {th }}$ or $10^{\text {th }}$ graders), and the rest is for $10^{\text {th }}$ graders. 
Figure 6: The effect of approving various types of additional funding for school districts on per pupil total expenditure.

Panel A) Operating expenditure (an additional \$1,000/year (in 2015 dollars) per pupil)

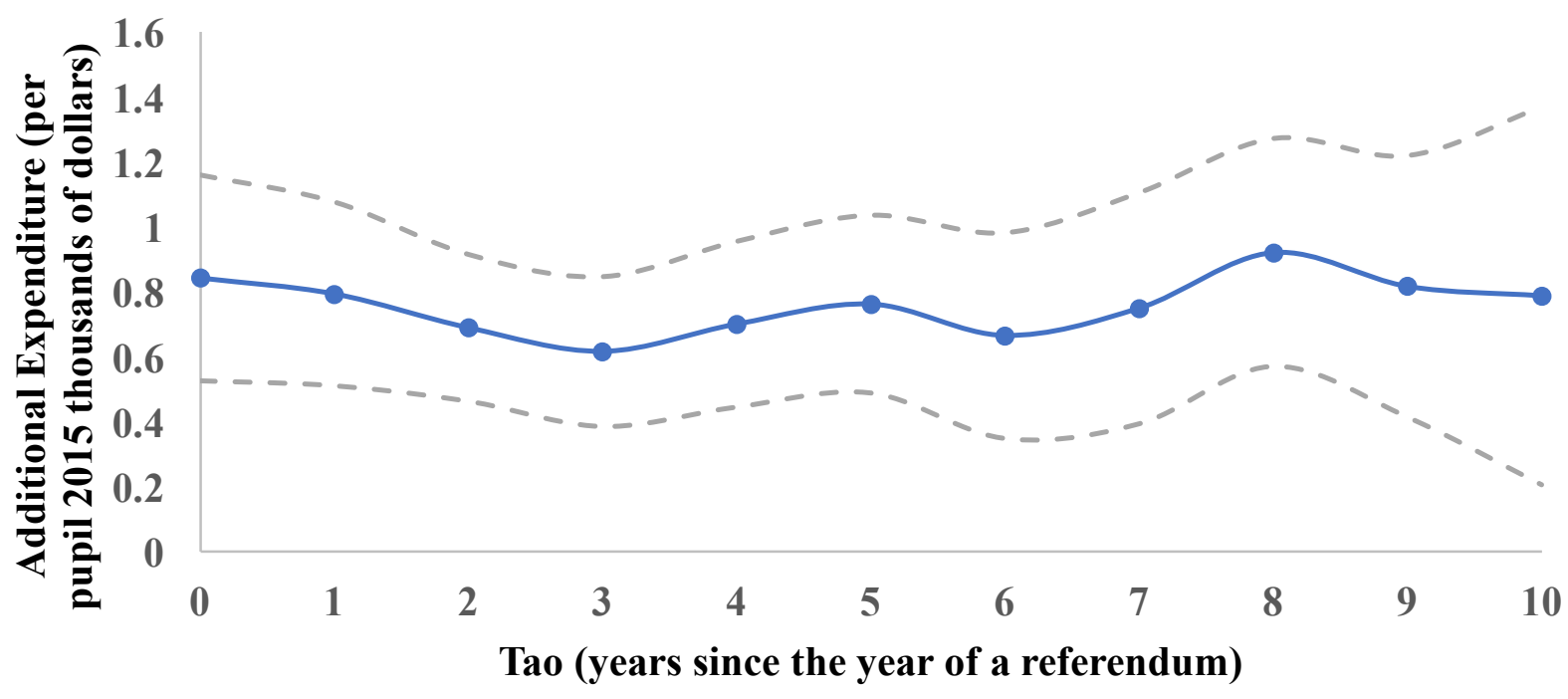

Panel B) Minor Capital expenditure (an additional \$1,000/year (in 2015 dollars) per pupil)

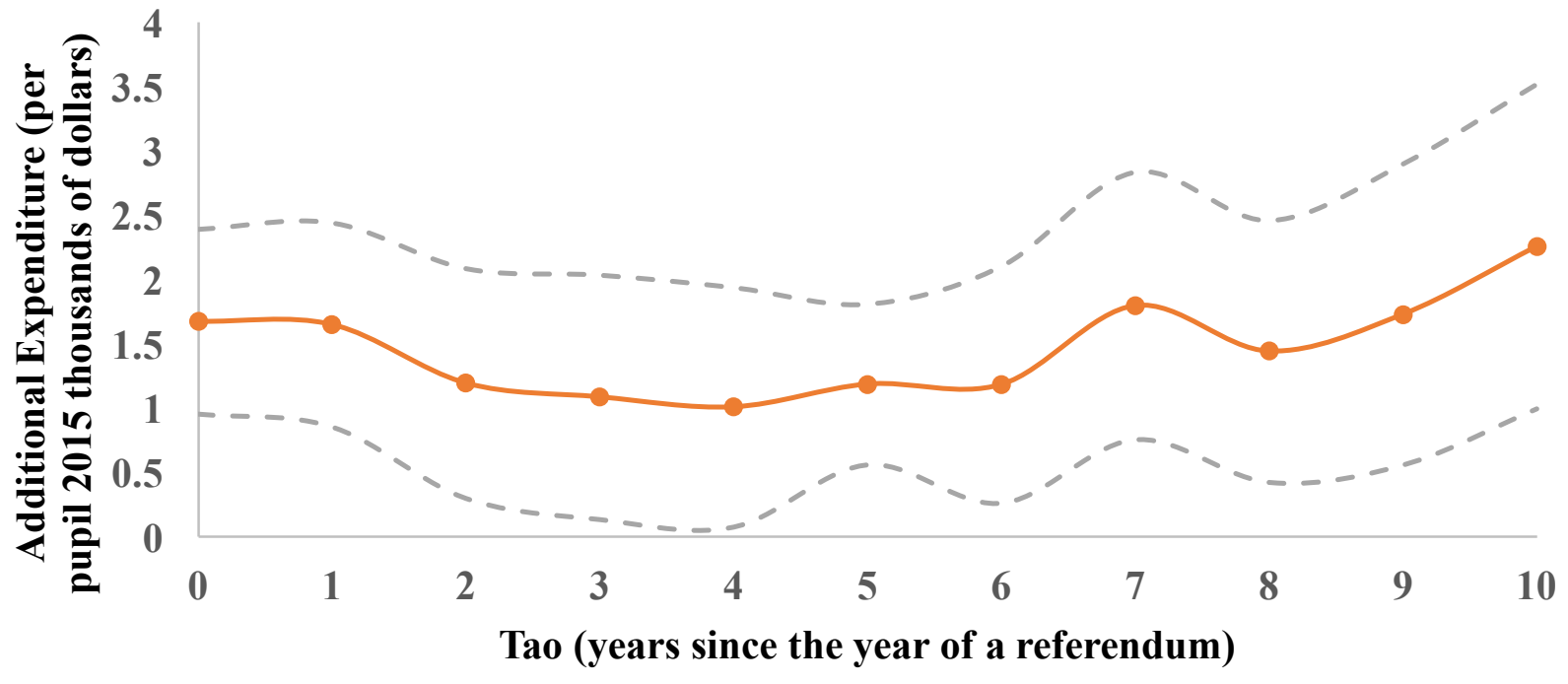




\section{Panel C) Major Capital expenditure (an additional \$1,000/project (in 2015 dollars) per pupil)}

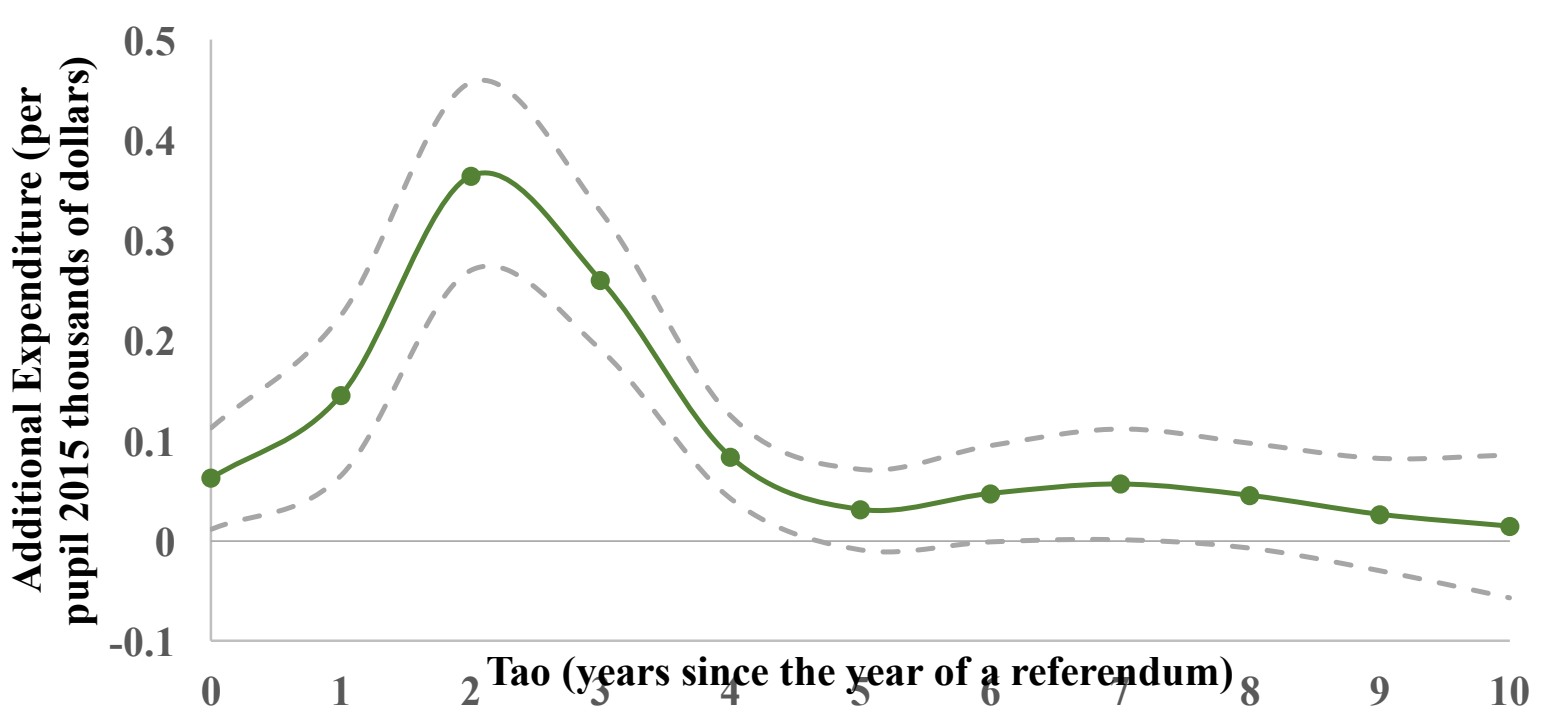

Sources: NCES, OSOS, ODT, and own calculations.

Notes: The data includes 602 Ohio school districts and 5174 referenda included in this paper. The graphs show simple ITT effects estimated separately for each Tao using equation (22). In each model, the dependent variable is the per pupil total expenditure (measured in thousands of 2015 dollars) Tao years following a referendum. The three main variables of interest graphed in Panels A, B, and C are the size of various additional expenditure approved for a school district (i.e. operating, minor capital, and major capital expenditures, respectively). These variables are also in per pupil thousands of 2015 dollars (the operating and minor capital expenditures are per year, while the major capital expenditure is per project). The solid line in each graph is the ITT effect and the dashed lines are the $90 \%$ confidence intervals. 
Figure 7: The effect of approving major capital expenditures on math proficiency of students.

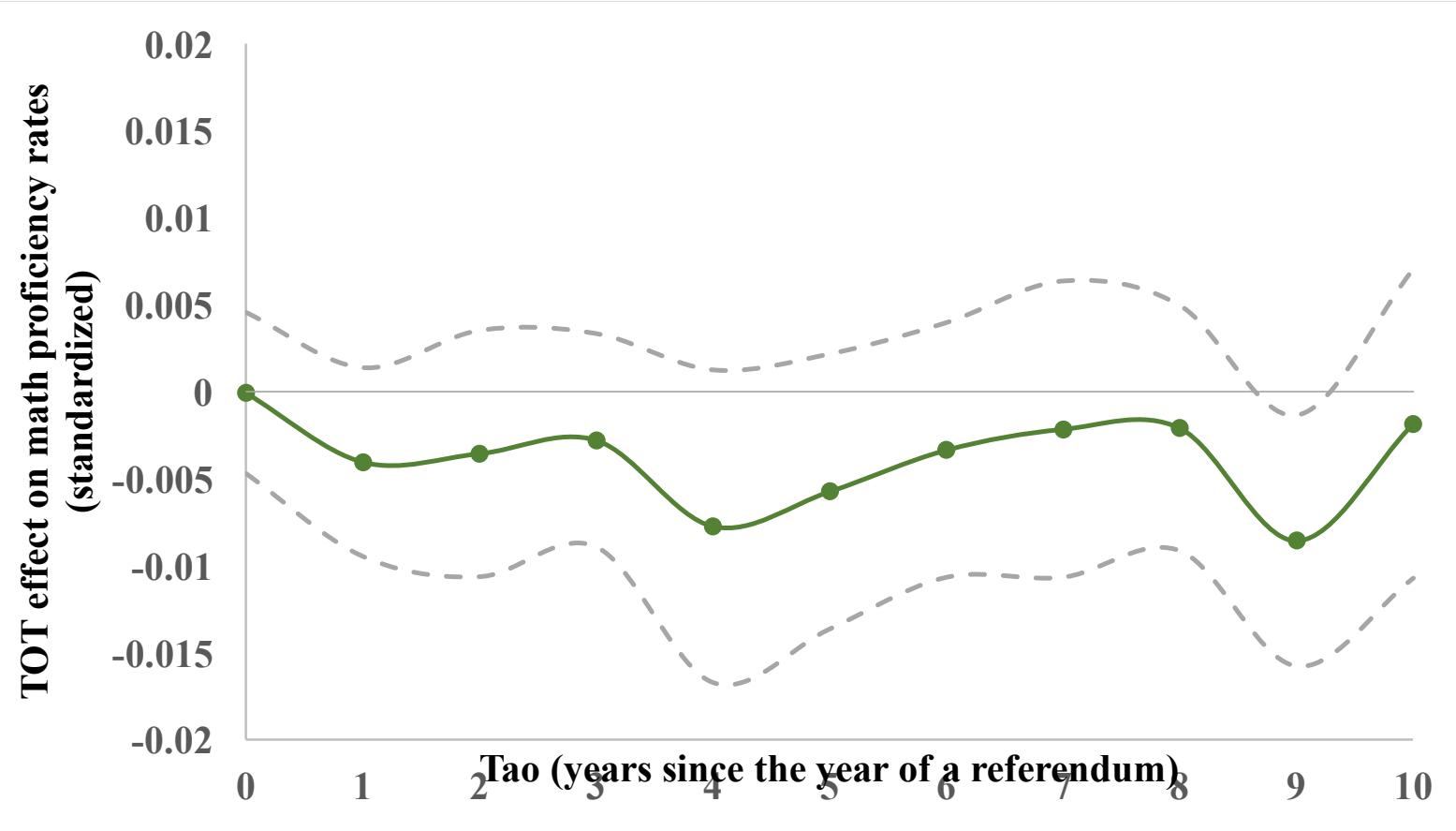

Note: The solid line is the TOT effect calculated using the DID-Recursive estimator introduced in equation (30), which is based on ITT values estimated using a model based on equation (31) using $\mathrm{L}=10$. Please see the methodology section for the list of control variables. The total number of observations is 313,165 . The main variable of interest (which the effect for is shown above) is the size of an approved major capital expenditure measured in per pupil thousands of constant-2015 dollars. The standardized math proficiency rates are for students subjected to Ohio high school graduation tests. The dashed lines represent $90 \%$ confidence intervals. 
Table 1: Year-by-year summary statistics of Ohio school district referenda (1996 to 2015)

Panel A. Bond referenda

\begin{tabular}{cccccc}
\hline \hline Year & $\begin{array}{c}\text { Number of } \\
\text { referenda }\end{array}$ & $\begin{array}{c}\text { Average size of a } \\
\text { project } \\
\text { (Millions of \$2015) }\end{array}$ & $\begin{array}{c}\text { Average size per } \\
\text { pupil per project } \\
\text { (\$2015) }\end{array}$ & Length & \% Pass \\
\hline 1996 & 65 & 22.72 & 8234.85 & 25.02 & 26.15 \\
1997 & 105 & 17.78 & 6942.65 & 24.51 & 42.86 \\
1998 & 117 & 19.85 & 8047.28 & 24.68 & 39.32 \\
1999 & 129 & 15.75 & 6918.31 & 24.81 & 55.81 \\
2000 & 138 & 26.00 & 10358.78 & 24.96 & 61.59 \\
2001 & 84 & 27.26 & 8976.53 & 25.35 & 50.00 \\
2002 & 93 & 47.27 & 11251.78 & 26.60 & 44.09 \\
2003 & 96 & 34.44 & 11386.88 & 27.29 & 33.33 \\
2004 & 88 & 26.17 & 9809.57 & 27.02 & 44.32 \\
2005 & 79 & 28.56 & 11394.28 & 27.82 & 34.18 \\
2006 & 77 & 21.27 & 8907.96 & 26.64 & 37.66 \\
2007 & 82 & 20.76 & 8756.38 & 26.89 & 34.15 \\
2008 & 93 & 31.23 & 9931.79 & 27.56 & 44.09 \\
2009 & 60 & 23.22 & 11661.87 & 30.43 & 35.00 \\
2010 & 60 & 28.49 & 12962.55 & 33.72 & 31.67 \\
2011 & 38 & 24.88 & 10694.71 & 32.21 & 26.32 \\
2012 & 44 & 27.95 & 11180.98 & 31.73 & 47.73 \\
2013 & 46 & 33.35 & 13193.51 & 34.02 & 39.13 \\
2014 & 38 & 37.87 & 14694.79 & 34.22 & 42.11 \\
2015 & 24 & 37.31 & 13134.40 & 35.21 & 66.67 \\
\hline \hline & & & & & \\
\hline
\end{tabular}


Panel B. Levy referenda

\begin{tabular}{|c|c|c|c|c|c|c|c|}
\hline Year & $\begin{array}{l}\text { Number of } \\
\text { referenda }\end{array}$ & $\begin{array}{c}\text { \% Capital } \\
\text { exp. }\end{array}$ & $\begin{array}{c}\text { Average size per } \\
\text { year } \\
\text { (Millions of \$2015) } \\
\end{array}$ & $\begin{array}{l}\text { Average size } \\
\text { per pupil per } \\
\text { year }(\$ 2015) \\
\end{array}$ & Length & $\%$ CPT & \% Pass \\
\hline 1996 & 149 & 36.91 & 2.87 & 637.72 & 5.05 & 25.50 & 63.09 \\
\hline 1997 & 289 & 36.33 & 1.66 & 593.60 & 5.54 & 13.84 & 66.78 \\
\hline 1998 & 277 & 38.27 & 2.15 & 607.42 & 6.29 & 15.88 & 65.70 \\
\hline 1999 & 305 & 45.90 & 1.90 & 601.64 & 7.54 & 16.07 & 71.15 \\
\hline 2000 & 310 & 36.45 & 2.86 & 670.65 & 7.33 & 20.00 & 78.06 \\
\hline 2001 & 255 & 34.51 & 2.19 & 712.60 & 6.22 & 17.65 & 71.76 \\
\hline 2002 & 255 & 30.20 & 2.33 & 784.01 & 5.68 & 19.61 & 67.84 \\
\hline 2003 & 314 & 28.34 & 2.70 & 862.71 & 5.83 & 23.25 & 59.24 \\
\hline 2004 & 479 & 23.59 & 3.31 & 861.29 & 5.97 & 27.14 & 47.81 \\
\hline 2005 & 393 & 24.17 & 3.03 & 859.16 & 6.01 & 22.14 & 58.78 \\
\hline 2006 & 321 & 33.02 & 2.80 & 791.06 & 6.48 & 22.74 & 55.45 \\
\hline 2007 & 318 & 36.48 & 2.34 & 712.56 & 6.38 & 24.21 & 56.60 \\
\hline 2008 & 327 & 33.64 & 3.14 & 743.28 & 6.40 & 28.13 & 59.02 \\
\hline 2009 & 285 & 27.72 & 2.63 & 713.84 & 6.69 & 20.70 & 63.51 \\
\hline 2010 & 338 & 22.49 & 2.63 & 818.06 & 6.67 & 25.74 & 55.03 \\
\hline 2011 & 300 & 22.00 & 2.98 & 803.29 & 5.87 & 27.67 & 55.33 \\
\hline 2012 & 276 & 22.46 & 2.84 & 743.20 & 6.06 & 22.83 & 60.14 \\
\hline 2013 & 278 & 24.82 & 2.33 & 781.32 & 6.22 & 28.06 & 58.99 \\
\hline 2014 & 247 & 30.36 & 1.81 & 701.27 & 5.81 & 22.27 & 69.23 \\
\hline 2015 & 106 & 33.96 & 1.44 & 714.30 & 6.36 & 30.19 & 78.30 \\
\hline
\end{tabular}


Panel C. Income tax referenda

\begin{tabular}{|c|c|c|c|c|c|c|c|}
\hline Year & $\begin{array}{l}\text { Number of } \\
\text { referenda }\end{array}$ & $\begin{array}{c}\text { \% Capital } \\
\text { exp. }\end{array}$ & $\begin{array}{c}\text { Average size per } \\
\text { year } \\
\text { (Millions of \$2015) }\end{array}$ & $\begin{array}{l}\text { Average size } \\
\text { per pupil per } \\
\text { year }(\$ 2015) \\
\end{array}$ & Length & $\%$ CPT & $\%$ Pass \\
\hline 1996 & 23 & 8.70 & 2.29 & 840.43 & 5.09 & 52.17 & 26.09 \\
\hline 1997 & 21 & 0.00 & 1.99 & 917.29 & 6.05 & 9.52 & 38.10 \\
\hline 1998 & 20 & 0.00 & 1.25 & 943.56 & 4.47 & 25.00 & 35.00 \\
\hline 1999 & 25 & 8.00 & 1.43 & 905.89 & 5.00 & 48.00 & 52.00 \\
\hline 2000 & 37 & 5.41 & 1.76 & 1110.55 & 5.30 & 27.03 & 35.14 \\
\hline 2001 & 19 & 10.53 & 1.58 & 1002.98 & 5.00 & 42.11 & 36.84 \\
\hline 2002 & 27 & 3.70 & 1.80 & 1062.05 & 5.11 & 33.33 & 40.74 \\
\hline 2003 & 47 & 0.00 & 1.97 & 1202.09 & 4.86 & 40.43 & 34.04 \\
\hline 2004 & 85 & 1.18 & 1.52 & 1087.30 & 4.85 & 37.65 & 36.47 \\
\hline 2005 & 79 & 2.53 & 1.57 & 1115.05 & 4.94 & 39.24 & 32.91 \\
\hline 2006 & 76 & 3.95 & 2.47 & 1153.11 & 7.10 & 31.58 & 43.42 \\
\hline 2007 & 63 & 12.70 & 2.33 & 1227.05 & 6.63 & 26.98 & 33.33 \\
\hline 2008 & 59 & 13.56 & 2.21 & 1047.58 & 8.88 & 44.07 & 27.12 \\
\hline 2009 & 50 & 12.00 & 1.25 & 1098.26 & 9.65 & 20.00 & 64.00 \\
\hline 2010 & 67 & 7.46 & 2.01 & 1159.75 & 7.39 & 23.88 & 49.25 \\
\hline 2011 & 48 & 4.17 & 2.78 & 1159.56 & 5.56 & 33.33 & 31.25 \\
\hline 2012 & 40 & 2.50 & 2.35 & 1317.56 & 6.03 & 27.50 & 42.50 \\
\hline 2013 & 49 & 6.12 & 1.90 & 1242.20 & 6.14 & 24.49 & 51.02 \\
\hline 2014 & 33 & 21.21 & 0.48 & 804.70 & 7.26 & 18.18 & 48.48 \\
\hline
\end{tabular}

Sources: Referendum reports from the OSOS, school district property and income tax data from ODT, and own calculations.

Notes: The data covers all referenda related to the 612 traditional school districts in Ohio. The year refers to the calendar year that a referendum takes place. The average size (and average size per pupil) refers to the dollar value associated with a tax proposal on the ballot. The dollar value for bond measures (Panel A) is based on the total dollar value of a bond recorded in the referendum reports. The size of a levy (Panel B) is calculated based on the millage rate of the issue on the ballot and the total taxable value of the properties in a school district, and it is for one year. The dollar values for the income tax measures (Panel C) are imputed based on the total "federal adjusted gross income" of individuals living in a school district, and it is for one year. "\% Capital exp." refers to the issues on the ballot that are for the minor capital expenditures purposes only. Bond referenda are all for major capital expenditure purposes. Length refers to the average length of issues that are not considered for "continuing period of time (CPT)". "\% CPT" refers to the percentage of the issues that are considered for CPT. Panel C does not include the data for year 2015 because as of writing of this paper, ODT has not released the data for this year. 
Table 2: Aggregated summary of the referendum data.

\begin{tabular}{|c|c|c|c|c|c|c|c|}
\hline $\begin{array}{l}\text { The type of } \\
\text { referendum }\end{array}$ & $\begin{array}{c}\text { Number of } \\
\text { unique } \\
\text { school dist. }\end{array}$ & $\begin{array}{c}\text { Number of } \\
\text { referenda }\end{array}$ & $\begin{array}{c}\text { Per pupil average } \\
\text { size requested } \\
(2015 \$)\end{array}$ & $\begin{array}{c}\text { Length } \\
\text { (year) }\end{array}$ & $\begin{array}{c}\% \\
\text { CPT }\end{array}$ & $\begin{array}{c}\% \\
\text { Pass }\end{array}$ & $\begin{array}{c}\% \\
\text { Close }\end{array}$ \\
\hline Operational Exp. & 545 & 3350 & 984.37/year & 5.24 & 26.15 & 58.39 & 32.15 \\
\hline \multicolumn{8}{|l|}{ Capital Exp. } \\
\hline Minor & 508 & 1452 & 288.87/year & 8.76 & 22.80 & 68.60 & 28.24 \\
\hline Major & 523 & 1074 & 10185.31/life-time & 27.29 & - & 45.72 & 37.43 \\
\hline
\end{tabular}

Sources: Referendum reports from the OSOS and own calculations.

Notes: Only referenda related to the first time a school district requested additional funding in the form of a new tax to be commenced in a specific year are included. The data covers years from 1996 to 2015 for all 602 Ohio school districts included in this analysis. The total number of unique school districts with at least one referendum over this period is 594. Length refers to the average length of issues that are not considered for "continuing period of time (CPT)". For major capital expenditures, Length refers to the number of years it will take to repay the principal and interests of the issued bonds. "\% CPT" refers to the percentage of the issues that are considered for CPT. "\% Close" refers to the percentage of the referenda that have a vote margin between $45 \%$ and $55 \%$ (included) in favor of the issue on the ballot.

Table 3. The district level descriptive statistics of main variables of interest

\begin{tabular}{lcccccc}
\hline Variable & $\begin{array}{c}\text { Years } \\
\text { Included }\end{array}$ & Mean & $\begin{array}{c}\text { Standard } \\
\text { Deviation }\end{array}$ & Min & Max & Median \\
\hline Number of Students & $1997-2013$ & 2850 & 4610 & 67 & 76504 & 1787 \\
$\begin{array}{l}\text { Per Pupil Expenditure } \\
\text { (\$2015) }\end{array}$ & $1997-2013$ & 11879.9 & 3933.61 & 1664.04 & 147527.70 & 10866.16 \\
$\begin{array}{l}\text { Average Expenditure } \\
\text { on Instructional Staff } \\
\text { (\$2015) }\end{array}$ & $1997-2013$ & 95969.62 & 14065.76 & 39120.14 & 170903.00 & 94462.06 \\
$\begin{array}{l}\text { Student to Teacher } \\
\text { Ratio }\end{array}$ & $1997-2013$ & 17.39 & 2.36 & 3.70 & 53.50 & 17.36 \\
$\begin{array}{l}\text { Attendance Rate (\%) } \\
\begin{array}{l}\text { Disciplinary Actions } \\
\text { per 100 Students }\end{array}\end{array}$ & $2005-2015$ & 96.13 & 1.67 & 89.00 & 97.50 & 97.50 \\
\hline \hline
\end{tabular}

Sources: NCES, ODE and own calculations.

Notes: The data includes 602 out of 612 Ohio school districts that are included in this paper. Year corresponds to the Fall semester of a school year. 
Table 4. Parallel trend tests for the main variables of interest.

\begin{tabular}{cccccc}
$\begin{array}{c}\text { Math } \\
\text { proficiency rate } \\
\text { (Standardized) }\end{array}$ & $\begin{array}{c}\text { Per Pupil } \\
\text { Expenditure } \\
\mathbf{( \$ 2 0 1 5 )}\end{array}$ & $\begin{array}{c}\text { Average } \\
\text { Expenditure on } \\
\text { Instructional } \\
\text { Staff (\$2015) }\end{array}$ & $\begin{array}{c}\text { Student- } \\
\text { teacher } \\
\text { ratio }\end{array}$ & $\begin{array}{c}\text { Attendance } \\
\text { rate (\%) }\end{array}$ & $\begin{array}{c}\text { Disciplinary } \\
\text { actions } \\
\text { (per 100 } \\
\text { students) }\end{array}$ \\
\hline
\end{tabular}

\begin{tabular}{|c|c|c|c|c|c|c|}
\hline $\begin{array}{l}\text { Operating } \\
\text { exp. * Tao }\end{array}$ & $\begin{array}{l}-0.00132 \\
(0.00732)\end{array}$ & $\begin{array}{c}0.04948 \\
(0.04651)\end{array}$ & $\begin{array}{c}0.06395 \\
(0.09835)\end{array}$ & $\begin{array}{c}0.02541 \\
(0.02149)\end{array}$ & $\begin{array}{l}0.00033 * \\
(0.00020)\end{array}$ & $\begin{array}{l}-0.23435 \\
(0.23251)\end{array}$ \\
\hline $\begin{array}{l}\text { Minor Capital } \\
\text { exp. * Tao }\end{array}$ & $\begin{array}{c}0.00085 \\
(0.02794)\end{array}$ & $\begin{array}{c}0.06800 \\
(0.15048)\end{array}$ & $\begin{array}{c}0.46544 \\
(0.55022)\end{array}$ & $\begin{array}{c}0.09675 \\
(0.08152)\end{array}$ & $\begin{array}{c}0.00007 \\
(0.00060)\end{array}$ & $\begin{array}{c}0.39178 \\
(0.54312)\end{array}$ \\
\hline $\begin{array}{l}\text { Major Capital } \\
\text { exp. * Tao }\end{array}$ & $\begin{array}{l}-0.00088 \\
(0.00120)\end{array}$ & $\begin{array}{l}-0.00707 * \\
(0.00367)\end{array}$ & $\begin{array}{l}-0.00870 \\
(0.01671)\end{array}$ & $\begin{array}{l}-0.00164 \\
(0.00416)\end{array}$ & $\begin{array}{c}0.00004 \\
(0.00004)\end{array}$ & $\begin{array}{l}-0.00471 \\
(0.03113)\end{array}$ \\
\hline \multicolumn{7}{|c|}{ Panel B. with controls for vote share } \\
\hline $\begin{array}{l}\text { Operating } \\
\text { exp. * Tao }\end{array}$ & $\begin{array}{l}-0.00165 \\
(0.00733)\end{array}$ & $\begin{array}{c}0.04416 \\
(0.04704)\end{array}$ & $\begin{array}{c}0.04831 \\
(0.09795)\end{array}$ & $\begin{array}{c}0.02466 \\
(0.02145)\end{array}$ & $\begin{array}{l}0.00032 \\
(0.0002)\end{array}$ & $\begin{array}{l}-0.23296 \\
(0.23353)\end{array}$ \\
\hline $\begin{array}{l}\text { Minor Capital } \\
\text { exp. * Tao }\end{array}$ & $\begin{array}{c}0.00050 \\
(0.02797)\end{array}$ & $\begin{array}{c}0.06513 \\
(0.15015)\end{array}$ & $\begin{array}{c}0.42763 \\
(0.55457)\end{array}$ & $\begin{array}{c}0.09084 \\
(0.08132)\end{array}$ & $\begin{array}{l}0.00002 \\
(0.0006)\end{array}$ & $\begin{array}{c}0.43143 \\
(0.53511)\end{array}$ \\
\hline $\begin{array}{l}\text { Major Capital } \\
\text { exp. * Tao }\end{array}$ & $\begin{array}{l}-0.00086 \\
(0.00120)\end{array}$ & $\begin{array}{l}-0.00535 \\
(0.00367)\end{array}$ & $\begin{array}{l}-0.01027 \\
(0.01662)\end{array}$ & $\begin{array}{l}-0.00194 \\
(0.00417)\end{array}$ & $\begin{array}{c}0.00004 \\
(0.00003)\end{array}$ & $\begin{array}{l}-0.00482 \\
(0.03118)\end{array}$ \\
\hline $\begin{array}{l}\text { Number of } \\
\text { Observations }\end{array}$ & 22638 & 18642 & 18643 & 18515 & 10425 & 10425 \\
\hline
\end{tabular}

Sources: NCES, ODE, ODT, OSOS, David Brasington personal data base for district level math proficiency rates, and own calculations.

Notes: Standard errors are clustered at the school district level. *,**, and *** represent significance levels of $10 \%$, $5 \%$ and $1 \%$, respectively. The data includes 602 out of 612 Ohio school districts that are included in this paper. Math proficiency rate is for students that are subjected to the Ohio high school graduation tests and are standardized for each year. Panel A regresses an outcome of interest on the following variables: three variables for the type of per pupil expenditures (in thousands of 2015 dollars) proposed (i.e. operating, minor capital, and major capital expenditures); a relative time trend variable, Tao, that takes values $-3,-2$, and -1 depending on the year that the outcome of interest is measured relative to the year of a referendum (e.g. -1 means the outcome of interest is measured one year before a referendum); three interaction terms between Tao and the three variables mentioned before (these interaction terms are the main variables of interest and reported in the above table); a control variable for the state provided additional funding for major capital projects; three indicator variables to identify the type of the proposed tax (i.e. whether it is a new tax, renewal/replacement of an existing one, or removal/reduction of an existing one); and school district and calendar year fixed effects. Regression models for Panel B have the same variables and three polynomials of order three in vote share for each type of referendum (i.e. operating, minor capital, and major capital expenditures). 
Table 5. The Impact of approving various types of additional funding on the school district level standardized math proficiency rate of students who are subject to the Ohio high school graduation tests.

\begin{tabular}{|c|c|c|c|c|c|c|}
\hline \multirow{2}{*}{$\begin{array}{l}\text { Approved type } \\
\text { of expenditure }\end{array}$} & \multicolumn{6}{|c|}{ Years relative to the commencement year of a tax measure $(\tau)$} \\
\hline & $\tau=0$ & $\tau=1$ & $\tau=2$ & $\tau=3$ & $\tau=4$ & $\tau=5$ \\
\hline \multicolumn{7}{|c|}{ Panel A. ITT effects } \\
\hline Operating exp. & $\begin{array}{c}0.02568 \\
(0.01881)\end{array}$ & $\begin{array}{l}0.03098 * \\
(0.01876)\end{array}$ & $\begin{array}{c}0.01976 \\
(0.01952)\end{array}$ & $\begin{array}{c}0.02693 \\
(0.02195)\end{array}$ & $\begin{array}{c}0.03015 \\
(0.02171)\end{array}$ & $\begin{array}{c}0.01523 \\
(0.02342)\end{array}$ \\
\hline $\begin{array}{c}\text { Capital exp. } \\
\text { Minor }\end{array}$ & $\begin{array}{l}-0.00962 \\
(0.06527)\end{array}$ & $\begin{array}{l}-0.01275 \\
(0.06105)\end{array}$ & $\begin{array}{c}0.05255 \\
(0.06262)\end{array}$ & $\begin{array}{c}0.01689 \\
(0.07007)\end{array}$ & $\begin{array}{l}-0.08442 \\
(0.08024)\end{array}$ & $\begin{array}{c}0.01768 \\
(0.07743)\end{array}$ \\
\hline Major & $\begin{array}{l}-0.00015 \\
(0.00285)\end{array}$ & $\begin{array}{l}-0.00414 \\
(0.00327)\end{array}$ & $\begin{array}{l}-0.00327 \\
(0.00423)\end{array}$ & $\begin{array}{l}-0.00208 \\
(0.00349)\end{array}$ & $\begin{array}{l}-0.00709 \\
(0.00524)\end{array}$ & $\begin{array}{l}-0.00465 \\
(0.00448)\end{array}$ \\
\hline \multicolumn{7}{|c|}{ Panel B. TOT effects: DID-Recursive } \\
\hline Operating exp. & $\begin{array}{c}0.02568 \\
(0.01881)\end{array}$ & $\begin{array}{l}0.03328 * \\
(0.01980)\end{array}$ & $\begin{array}{c}0.02173 \\
(0.02065)\end{array}$ & $\begin{array}{c}0.02363 \\
(0.02103)\end{array}$ & $\begin{array}{c}0.02281 \\
(0.02120)\end{array}$ & $\begin{array}{c}0.00375 \\
(0.02094)\end{array}$ \\
\hline $\begin{array}{c}\text { Capital exp. } \\
\text { Minor }\end{array}$ & $\begin{array}{l}-0.00962 \\
(0.06527)\end{array}$ & $\begin{array}{l}-0.00545 \\
(0.06085)\end{array}$ & $\begin{array}{c}0.06351 \\
(0.06115)\end{array}$ & $\begin{array}{c}0.02489 \\
(0.06781)\end{array}$ & $\begin{array}{l}-0.07497 \\
(0.07566)\end{array}$ & $\begin{array}{c}0.01864 \\
(0.07045)\end{array}$ \\
\hline Major & $\begin{array}{l}-0.00015 \\
(0.00285)\end{array}$ & $\begin{array}{l}-0.00413 \\
(0.00334)\end{array}$ & $\begin{array}{l}-0.00370 \\
(0.00434)\end{array}$ & $\begin{array}{l}-0.00291 \\
(0.00376)\end{array}$ & $\begin{array}{l}-0.00785 \\
(0.00551)\end{array}$ & $\begin{array}{l}-0.00581 \\
(0.00485)\end{array}$ \\
\hline \multicolumn{7}{|c|}{ Panel C. TOT effects: One-Step } \\
\hline Operating exp. & $\begin{array}{c}0.00854 \\
(0.02842)\end{array}$ & $\begin{array}{c}0.08240 * * \\
(0.03300)\end{array}$ & $\begin{array}{l}0.05851 * \\
(0.03297)\end{array}$ & $\begin{array}{l}0.05959 * \\
(0.03452)\end{array}$ & $\begin{array}{c}0.04709 \\
(0.03349)\end{array}$ & $\begin{array}{c}0.02422 \\
(0.03264)\end{array}$ \\
\hline $\begin{array}{l}\text { Capital exp. } \\
\text { Minor }\end{array}$ & $\begin{array}{l}-0.07817 \\
(0.08078)\end{array}$ & $\begin{array}{c}0.05177 \\
(0.09818)\end{array}$ & $\begin{array}{c}0.04368 \\
(0.09202)\end{array}$ & $\begin{array}{c}0.00948 \\
(0.09690)\end{array}$ & $\begin{array}{l}-0.13847 \\
(0.10328)\end{array}$ & $\begin{array}{c}0.02328 \\
(0.09926)\end{array}$ \\
\hline Major & $\begin{array}{c}0.00069 \\
(0.00642)\end{array}$ & $\begin{array}{l}-0.01154 \\
(0.00725)\end{array}$ & $\begin{array}{l}-0.00555 \\
(0.00492)\end{array}$ & $\begin{array}{c}0.00038 \\
(0.00556)\end{array}$ & $\begin{array}{l}-0.00210 \\
(0.00487)\end{array}$ & $\begin{array}{l}-0.00632 \\
(0.00445)\end{array}$ \\
\hline
\end{tabular}

Notes: Clustered standard errors (at the school district level) are in parenthesis. *, **, and *** represent significance levels of $10 \%, 5 \%$ and $1 \%$, respectively. Parameter estimates represent the effect of approving additional expenditures (operating, minor capital, and major capital expenditures) for school districts (measured in per pupil constant-2015 thousands of dollars: per year for operating and minor capital expenditures and per project for major capital expenditures) on the standardized math proficiency rates of students subjected to Ohio high school graduation tests. The effects are measured in various points after the commencement year of a new tax ( $\tau=0$ represents the commencement year, $\tau=1$ represents one year after the commencement, and so on). All parameters in Panels A and C are estimated in two separate regressions based on equations (31) and (32) respectively (using $L=6$ and $\bar{\tau}=10$ in these two equations). Please see the methodology section for the list of control variables in each model. The total number of observations for Panels A and C are 217,554 and 5,407 respectively. Parameters in Panel B are estimated using equation (30) and are based on the parameters estimated in Panel A. 
Table 6. The Impact of approving various types of additional funding on the school district level student-to-teacher ratio, attendance rate, disciplinary actions per 100 students, and average expenditure on instructional staff

\begin{tabular}{|c|c|c|c|c|c|c|}
\hline \multirow{2}{*}{$\begin{array}{l}\text { Approved type } \\
\text { of expenditure }\end{array}$} & \multicolumn{6}{|c|}{ Years relative to the commencement year of a tax measure $(\tau)$} \\
\hline & $\tau=0$ & $\tau=1$ & $\tau=2$ & $\tau=3$ & $\tau=4$ & $\tau=5$ \\
\hline \multicolumn{7}{|c|}{ Panel A. Student to Teacher Ratio } \\
\hline Operating exp. & $\begin{array}{l}-0.02787 \\
(0.04697)\end{array}$ & $\begin{array}{l}-0.00086 \\
(0.05336)\end{array}$ & $\begin{array}{c}0.09850 \\
(0.06510)\end{array}$ & $\begin{array}{c}0.06604 \\
(0.06581)\end{array}$ & $\begin{array}{c}0.10176 \\
(0.07209)\end{array}$ & $\begin{array}{l}0.15265^{*} \\
(0.08375)\end{array}$ \\
\hline $\begin{array}{c}\text { Capital exp. } \\
\text { Minor }\end{array}$ & $\begin{array}{l}-0.05480 \\
(0.16790)\end{array}$ & $\begin{array}{c}0.03006 \\
(0.19563)\end{array}$ & $\begin{array}{c}0.28181 \\
(0.31599)\end{array}$ & $\begin{array}{c}0.20576 \\
(0.28475)\end{array}$ & $\begin{array}{c}0.39323 \\
(0.26955)\end{array}$ & $\begin{array}{c}0.32728 \\
(0.24275)\end{array}$ \\
\hline Major & $\begin{array}{c}0.00749 \\
(0.00663)\end{array}$ & $\begin{array}{c}0.00967 \\
(0.00967)\end{array}$ & $\begin{array}{l}-0.00031 \\
(0.01798)\end{array}$ & $\begin{array}{c}0.00736 \\
(0.01993)\end{array}$ & $\begin{array}{c}0.00260 \\
(0.02298)\end{array}$ & $\begin{array}{c}0.02035 \\
(0.01697)\end{array}$ \\
\hline \multicolumn{7}{|c|}{ Panel B. Attendance Rate (\%) } \\
\hline Operating exp. & $\begin{array}{l}-0.00052 \\
(0.00050)\end{array}$ & $\begin{array}{l}-0.00015 \\
(0.00052)\end{array}$ & $\begin{array}{l}-0.00031 \\
(0.00055)\end{array}$ & $\begin{array}{c}0.00072 \\
(0.00065)\end{array}$ & $\begin{array}{c}0.00004 \\
(0.00071)\end{array}$ & $\begin{array}{c}0.00052 \\
(0.00081)\end{array}$ \\
\hline $\begin{array}{c}\text { Capital exp. } \\
\text { Minor }\end{array}$ & $\begin{array}{c}0.00207 \\
(0.00235)\end{array}$ & $\begin{array}{c}0.00012 \\
(0.00155)\end{array}$ & $\begin{array}{l}0.00439^{*} \\
(0.00243)\end{array}$ & $\begin{array}{c}0.00585^{* *} \\
(0.00280)\end{array}$ & $\begin{array}{c}0.00306 \\
(0.00276)\end{array}$ & $\begin{array}{c}0.00372 \\
(0.00243)\end{array}$ \\
\hline Major & $\begin{array}{l}-0.00008 \\
(0.00010)\end{array}$ & $\begin{array}{l}-0.00004 \\
(0.00012)\end{array}$ & $\begin{array}{l}-0.00001 \\
(0.00015)\end{array}$ & $\begin{array}{c}0.00000 \\
(0.00016)\end{array}$ & $\begin{array}{l}-0.00006 \\
(0.00020)\end{array}$ & $\begin{array}{l}-0.00002 \\
(0.00023)\end{array}$ \\
\hline \multicolumn{7}{|c|}{ Panel C. Disciplinary Actions per 100 Students } \\
\hline Operating exp. & $\begin{array}{l}-0.37361 \\
(0.46043)\end{array}$ & $\begin{array}{c}0.14673 \\
(0.55436)\end{array}$ & $\begin{array}{c}0.14980 \\
(0.63090)\end{array}$ & $\begin{array}{l}-0.27716 \\
(0.72880)\end{array}$ & $\begin{array}{l}-0.22090 \\
(0.88782)\end{array}$ & $\begin{array}{c}0.29822 \\
(1.05472)\end{array}$ \\
\hline $\begin{array}{c}\text { Capital exp. } \\
\text { Minor }\end{array}$ & $\begin{array}{l}-1.00910 \\
(1.60407)\end{array}$ & $\begin{array}{c}0.07557 \\
(1.46063)\end{array}$ & $\begin{array}{l}-1.71141 \\
(1.52807)\end{array}$ & $\begin{array}{l}-3.24721 * \\
(1.82664)\end{array}$ & $\begin{array}{l}-1.28563 \\
(1.67178)\end{array}$ & $\begin{array}{l}-1.97486 \\
(1.98569)\end{array}$ \\
\hline Major & $\begin{array}{l}0.17498 * \\
(0.09431)\end{array}$ & $\begin{array}{c}0.10282 \\
(0.09618)\end{array}$ & $\begin{array}{c}0.02647 \\
(0.12038)\end{array}$ & $\begin{array}{c}0.11007 \\
(0.13316)\end{array}$ & $\begin{array}{c}0.02062 \\
(0.15289)\end{array}$ & $\begin{array}{l}-0.02683 \\
(0.24721)\end{array}$ \\
\hline \multicolumn{7}{|c|}{ Panel D. Average Expenditure on Instructional Staff (thousands of constant-2015 dollar) } \\
\hline Operating exp. & $\begin{array}{l}-0.01417 \\
(0.26585)\end{array}$ & $\begin{array}{c}0.29238 \\
(0.35133)\end{array}$ & $\begin{array}{c}0.83010 * * \\
(0.33373)\end{array}$ & $\begin{array}{c}1.01502 * * * \\
(0.34371)\end{array}$ & $\begin{array}{c}1.45571 * * * \\
(0.36753)\end{array}$ & $\begin{array}{c}1.85562 * * * \\
(0.39697)\end{array}$ \\
\hline $\begin{array}{c}\text { Capital exp. } \\
\text { Minor }\end{array}$ & $\begin{array}{l}-0.59512 \\
(1.05307)\end{array}$ & $\begin{array}{c}1.67479 * * \\
(0.71199)\end{array}$ & $\begin{array}{c}0.74101 \\
(1.25550)\end{array}$ & $\begin{array}{l}2.40150 * \\
(1.22659)\end{array}$ & $\begin{array}{c}3.75487 * * \\
(1.56205)\end{array}$ & $\begin{array}{l}2.62932 * \\
(1.54685)\end{array}$ \\
\hline Major & $\begin{array}{c}0.04691 \\
(0.04003)\end{array}$ & $\begin{array}{c}0.02067 \\
(0.05152)\end{array}$ & $\begin{array}{c}0.03000 \\
(0.06763)\end{array}$ & $\begin{array}{c}0.07799 \\
(0.06773)\end{array}$ & $\begin{array}{c}0.04075 \\
(0.07253)\end{array}$ & $\begin{array}{c}0.05940 \\
(0.07984)\end{array}$ \\
\hline
\end{tabular}

Notes: Clustered standard errors (at the school district level) are in parenthesis. *,**, and *** represent significance levels of $10 \%, 5 \%$ and $1 \%$, respectively. Parameter estimates represent the effect of approving additional expenditures (operating, minor capital, and major capital expenditures) for school districts (measured in per 
pupil constant-2015 thousands of dollars: per year for operating and minor capital expenditures and per project for major capital expenditures) on the dependent variable specified for each panel. The effects are measured in various points after the commencement year of a new tax $(\tau=0$ represents the commencement year, $\tau=1$ represents one year after the commencement, and so on). Parameters in each panel represent the TOT effects using the DID-Recursive estimator based on a separate equation (30) (in which $L=6$ ) and a corresponding equation (31). Please see the methodology section for the list of control variables. The total number of observations for each panel is as follows: A: 195,028; B and C: 88,476; D: 195,379.

Table 7. Robustness checks

\begin{tabular}{|c|c|c|c|c|c|c|}
\hline \multirow{2}{*}{$\begin{array}{l}\text { Approved type } \\
\text { of expenditure }\end{array}$} & \multicolumn{6}{|c|}{ Years relative to the commencement year of a tax measure $(\tau)$} \\
\hline & $\tau=0$ & $\tau=1$ & $\tau=2$ & $\tau=3$ & $\tau=4$ & $\tau=5$ \\
\hline \multicolumn{7}{|c|}{ Panel A. Reading proficiency rate (standardized) in Ohio high school graduation tests (OHSGT) } \\
\hline Operating exp. & $\begin{array}{c}0.01455 \\
(0.01652)\end{array}$ & $\begin{array}{c}0.04659 * * \\
(0.02100)\end{array}$ & $\begin{array}{c}0.06319 * * * \\
(0.02222)\end{array}$ & $\begin{array}{c}0.02741 \\
(0.02400)\end{array}$ & $\begin{array}{c}0.02790 \\
(0.02662)\end{array}$ & $\begin{array}{l}-0.00823 \\
(0.02747)\end{array}$ \\
\hline $\begin{array}{c}\text { Capital exp. } \\
\text { Minor }\end{array}$ & $\begin{array}{l}-0.01345 \\
(0.05805)\end{array}$ & $\begin{array}{c}0.04067 \\
(0.07070)\end{array}$ & $\begin{array}{c}0.08474 \\
(0.05289)\end{array}$ & $\begin{array}{c}0.02678 \\
(0.06456)\end{array}$ & $\begin{array}{l}-0.01990 \\
(0.05659)\end{array}$ & $\begin{array}{c}0.05916 \\
(0.06380)\end{array}$ \\
\hline Major & $\begin{array}{c}0.00528 \\
(0.00501)\end{array}$ & $\begin{array}{l}-0.00313 \\
(0.00489)\end{array}$ & $\begin{array}{l}-0.00693 \\
(0.00513)\end{array}$ & $\begin{array}{l}-0.00220 \\
(0.00541)\end{array}$ & $\begin{array}{l}-0.00266 \\
(0.00519)\end{array}$ & $\begin{array}{l}-0.00716 \\
(0.00528)\end{array}$ \\
\hline
\end{tabular}

Panel B. Math proficiency rate (standardized) in OHSGT using only close referenda

\begin{tabular}{ccccccc} 
Operating exp. & $0.04640^{*}$ & $0.06201 * *$ & 0.04392 & 0.04793 & 0.01176 & -0.01111 \\
& $(0.02391)$ & $(0.02978)$ & $(0.03805)$ & $(0.03404)$ & $(0.03937)$ & $(0.03573)$ \\
$\begin{array}{l}\text { Capital exp. } \\
\text { Minor }\end{array}$ & 0.00711 & 0.04099 & 0.09688 & 0.06263 & -0.08792 & 0.05486 \\
& $(0.06958)$ & $(0.06959)$ & $(0.06472)$ & $(0.07497)$ & $(0.08201)$ & $(0.07629)$ \\
& & & & & & \\
Major & 0.00012 & -0.00730 & $-0.01299 * *$ & -0.00834 & $-0.01878^{* * *}$ & $-0.01074 *$ \\
& $(0.00475)$ & $(0.00550)$ & $(0.00571)$ & $(0.00630)$ & $(0.00661)$ & $(0.00634)$ \\
\hline \hline
\end{tabular}

Notes: Clustered standard errors (at the school district level) are in parenthesis. ${ }^{*},{ }^{*}$, and $* * *$ represent significance levels of $10 \%, 5 \%$ and $1 \%$, respectively. Parameter estimates represent the effect of approving additional expenditures (operating, minor capital, and major capital expenditures) for school districts (measured in per pupil constant-2015 thousands of dollars: per year for operating and minor capital expenditures and per project for major capital expenditures) on the dependent variable specified for each panel. The effects are measured in various points after the commencement year of a new tax $(\tau=0$ represents the commencement year, $\tau=1$ represents one year after the commencement, and so on). Parameters in each panel represent the TOT effects using the DID-Recursive estimator based on a separate equation (30) (in which $L=6$ ) and a corresponding equation (31). Please see the methodology section for the list of control variables. The total number of observations for Panels A and B are 85,514 and 100,336 respectively. Close referenda used for Panel B are the referenda with vote shares between $45 \%$ and $55 \%$. 
Table 8. Pseudo regressions

\begin{tabular}{lcccccc}
\hline \hline & $\begin{array}{c}\text { Math } \\
\text { proficiency rate } \\
\text { (Standardized) }\end{array}$ & $\begin{array}{c}\text { Per Pupil } \\
\text { Expenditure } \\
\mathbf{( \$ 2 0 1 5 )}\end{array}$ & $\begin{array}{c}\text { Average } \\
\text { Expenditure on } \\
\text { Instructional } \\
\text { Staff (\$2015) }\end{array}$ & $\begin{array}{c}\text { Student- } \\
\text { teacher } \\
\text { ratio }\end{array}$ & $\begin{array}{c}\text { Attendance } \\
\text { rate (\%) }\end{array}$ & $\begin{array}{c}\text { Disciplinary } \\
\text { actions } \\
\text { (per 100 } \\
\text { students) }\end{array}$ \\
\hline Operating exp. & -0.00900 & 0.18296 & 0.20773 & 0.06485 & 0.00061 & -0.58581 \\
$(0.02278)$ & $(0.13333)$ & $(0.33219)$ & $(0.05271)$ & $(0.00064)$ & $(0.72762)$ \\
Capital exp. & -0.01987 & -0.28212 & 0.99794 & 0.14841 & -0.00072 & 1.17678 \\
$\quad$ Minor & $(0.08779)$ & $(0.35219)$ & $(1.47489)$ & $(0.26989)$ & $(0.00176)$ & $(1.63790)$ \\
& -0.00212 & 0.00133 & -0.04802 & -0.00141 & -0.00006 & -0.02724 \\
\multicolumn{1}{c}{ Major } & $(0.00362)$ & $(0.01075)$ & $(0.04924)$ & $(0.00828)$ & $(0.00013)$ & $(0.12640)$ \\
\hline $\begin{array}{l}\text { Number of } \\
\text { Observations }\end{array}$ & 10295 & 8616 & 8616 & 8562 & 4062 & 4062 \\
\hline \hline
\end{tabular}

Notes: Clustered standard errors (at the school district level) are in parenthesis. ${ }^{*}, * *$, and $* * *$ represent significance levels of $10 \%, 5 \%$ and $1 \%$, respectively. All parameter estimates are pseudo effects estimated in DID models in which observations for two years prior to a referendum $(\tau=-2)$ is considered as pretreatment period and observations related to one-year prior to a referendum $(\tau=-1)$ is considered as posttreatment period. The data is limited to only these two periods. Parameter estimates represent the (placebo) effect of approving additional expenditures (operating, minor capital, and major capital expenditures) for school districts (measured in per pupil constant-2015 thousands of dollars: per year for operating and minor capital expenditures and per project for major capital expenditures) on the dependent variable specified in each column. The model has a similar structure and covariates as equation (22). Please see the methodology section for the list of control variables. 
Table 9. The differential Impact of approving various types of additional funding on the school district level standardized math proficiency rate of students who are subject to the Ohio high school graduation tests who live in high vs. low poverty districts

\begin{tabular}{|c|c|c|c|c|c|c|}
\hline \multirow{2}{*}{$\begin{array}{l}\text { Approved type } \\
\text { of expenditure }\end{array}$} & \multicolumn{6}{|c|}{ Years relative to the commencement year of a tax measure $(\tau)$} \\
\hline & $\tau=0$ & $\tau=1$ & $\tau=2$ & $\tau=3$ & $\tau=4$ & $\tau=5$ \\
\hline \multicolumn{7}{|c|}{ Panel A. Higher poverty } \\
\hline Operating exp. & $\begin{array}{c}0.03733 \\
(0.06351)\end{array}$ & $\begin{array}{l}0.12346^{*} \\
(0.07008)\end{array}$ & $\begin{array}{c}0.10213 \\
(0.07479)\end{array}$ & $\begin{array}{l}0.18652 * * \\
(0.07683)\end{array}$ & $\begin{array}{c}0.12304 \\
(0.07536)\end{array}$ & $\begin{array}{c}0.04357 \\
(0.08521)\end{array}$ \\
\hline $\begin{array}{c}\text { Capital exp. } \\
\text { Minor }\end{array}$ & $\begin{array}{c}-0.53712^{* *} \\
(0.26190)\end{array}$ & $\begin{array}{c}-0.10472 \\
(0.26798)\end{array}$ & $\begin{array}{l}-0.01755 \\
(0.29012)\end{array}$ & $\begin{array}{l}-0.16513 \\
(0.27788)\end{array}$ & $\begin{array}{c}-0.45432 \\
(0.36608)\end{array}$ & $\begin{array}{c}-0.02478 \\
(0.35964)\end{array}$ \\
\hline Major & $\begin{array}{c}0.00165 \\
(0.00628)\end{array}$ & $\begin{array}{c}0.00412 \\
(0.00845)\end{array}$ & $\begin{array}{c}0.00983 \\
(0.00745)\end{array}$ & $\begin{array}{l}-0.00034 \\
(0.00825)\end{array}$ & $\begin{array}{c}0.01126 \\
(0.00873)\end{array}$ & $\begin{array}{c}0.00579 \\
(0.00812)\end{array}$ \\
\hline \multicolumn{7}{|c|}{ Panel B. Lower Poverty } \\
\hline Operating exp. & $\begin{array}{c}0.02431 \\
(0.02349)\end{array}$ & $\begin{array}{c}0.02613 \\
(0.02330)\end{array}$ & $\begin{array}{c}0.01088 \\
(0.02187)\end{array}$ & $\begin{array}{c}0.02589 \\
(0.02459)\end{array}$ & $\begin{array}{c}0.02603 \\
(0.01947)\end{array}$ & $\begin{array}{c}0.03413 \\
(0.02082)\end{array}$ \\
\hline $\begin{array}{l}\text { Capital exp. } \\
\text { Minor }\end{array}$ & $\begin{array}{c}0.00059 \\
(0.04739)\end{array}$ & $\begin{array}{l}-0.03975 \\
(0.08842)\end{array}$ & $\begin{array}{c}0.02143 \\
(0.05937)\end{array}$ & $\begin{array}{c}0.00832 \\
(0.07199)\end{array}$ & $\begin{array}{c}-0.03243 \\
(0.07663)\end{array}$ & $\begin{array}{c}-0.00314 \\
(0.06465)\end{array}$ \\
\hline Major & $\begin{array}{l}-0.00035 \\
(0.00380)\end{array}$ & $\begin{array}{l}-0.00309 \\
(0.00362)\end{array}$ & $\begin{array}{l}-0.00684^{*} \\
(0.00401)\end{array}$ & $\begin{array}{l}-0.00220 \\
(0.00453)\end{array}$ & $\begin{array}{c}-0.01254 * * * \\
(0.00470)\end{array}$ & $\begin{array}{c}-0.00820^{* *} \\
(0.00406)\end{array}$ \\
\hline
\end{tabular}

Notes: Clustered standard errors (at the school district level) are in parenthesis. ${ }^{*}, * *$, and $* * *$ represent significance levels of $10 \%, 5 \%$ and $1 \%$, respectively. Parameter estimates represent the effect of approving additional expenditures (operating, minor capital, and major capital expenditures) for school districts (measured in per pupil constant-2015 thousands of dollars: per year for operating and minor capital expenditures and per project for major capital expenditures) on the school district level standardized math proficiency rate of students who are subject to the Ohio high school graduation tests. The effects are measured in various points after the commencement year of a new tax ( $\tau=0$ represents the commencement year, $\tau=1$ represents one year after the commencement, and so on). Parameters in each panel represent the TOT effects using the DID-Recursive estimator based on a separate equation (30) (in which $L=6$ ) and a corresponding equation (31). Please see the methodology section for the list of control variables. The total number of observations for Panels A and B are 169,558 and 176,400 respectively. Panel A (B) values are estimated using only the portion of data that belongs to the school districts with top (bottom) $30 \%$ poverty rates among children living in that school district in 1995, i.e. about 180 school districts. About 73\% (70\%) of these school districts are still in the same group in 2015 . 